\title{
Preparación y caracterización de membranas poliméricas electrohiladas de policaprolactona y quitosano para la liberación controlada de clorhidrato de tiamina
}

\author{
Preparation and Characterization of Electrospun Polymeric Membranes of \\ Polycaprolactone and Chitosan for Controlled Release of Thiamine Chlorhydrate
}

\author{
Ángela Patricia Sánchez Cepeda $\mathrm{a}^{*}$ \\ Ricardo Vera-Graziano ${ }^{\mathrm{b}}$ \\ Efrén de Jesús Muñoz-Prieto ${ }^{c}$ \\ Edwin Yesid Gómez-Pachón ${ }^{\mathrm{d}}$ \\ María Josefa Bernad-Bernad ${ }^{\text {e }}$ \\ Alfredo Maciel-Cerda ${ }^{\mathrm{f}}$
}

Recepción: 22-dic-2015

Aceptación: 03-jun-2016

\section{Resumen}

Actualmente existen importantes investigaciones sobre la preparación de membranas porosas bioabsorbibles que permiten la liberación controlada de fármacos y vitaminas. En este estudio se propuso preparar membranas porosas a partir de policaprolactona (PCL) y quitosano (CS) bajo la técnica de electrohilado aplicando diferentes parámetros con el fin de evaluar sus características internas y propiedades para una potencial aplicación como liberador del clorhidrato de tiamina (Vitamina $B_{1}$ ). Además se desarrolló el estudio de la cinética de liberación In vitro del clorhidrato de tiamina (TC) con las membranas preparadas. Se obtuvo una membrana polimérica a partir de una disolución de PCL/CS w/w (8:1) y otra de PCL/CS w/w

\footnotetext{
${ }^{a}$ Escuela de Ciencias Químicas, Facultad de Ciencias, Universidad Pedagógica y Tecnológica de Colombia-UPTC. 150002. Grupo de Investigación en Desarrollo y Aplicaciones de Nuevos Materiales-DANUM, Universidad Pedagógica y Tecnológica de ColombiaUPTC.

*angelita1125766@hotmail.com

b Instituto de Investigaciones en Materiales-IIM, Universidad Nacional Autónoma de México-UNAM, Circuito Exterior, Ciudad Universitaria, Coyoacán, México, Distrito Federal. 04510.

${ }^{c}$ Escuela de Ciencias Químicas, Facultad de Ciencias, Universidad Pedagógica y Tecnológica de Colombia-UPTC. 150002.Grupo de Investigación en Desarrollo y Aplicaciones de Nuevos Materiales-DANUM, Universidad Pedagógica y Tecnológica de ColombiaUPTC, 150002.

${ }^{\mathrm{d}}$ Grupo de Investigación en Desarrollo y Aplicaciones de Nuevos Materiales-DANUM, Universidad Pedagógica y Tecnológica de Colombia-UPTC, 150002. Escuela de Diseño Industrial, Facultad sede Duitama, Universidad Pedagógica y Tecnológica de Colombia-UPTC.

eDepartamento de Farmacia en la Facultad de Química-UNAM, Circuito Universitario 3000, Ciudad Universitaria, Coyoacán, México, Distrito Federal.

${ }^{\mathrm{f}}$ Instituto de Investigaciones en Materiales-IIM, Universidad Nacional Autónoma de México-UNAM, Circuito Exterior, Ciudad Universitaria, Coyoacán, México, Distrito Federal.
} 
(10:1) con una carga del TC respecto a la PCL w/w (20:1) disueltos en TFA/DCM v/v (80:20), con mínimos defectos como bulbos y diámetros uniformes. Las fibras fueron caracterizadas con apoyo de técnicas de Microscopia Electrónica de Barrido (SEM), Espectroscopia Infrarroja (FTIR), Calorimetría Diferencial de Barrido (DSC), Análisis Termogravimétrico (TGA), Difracción de Rayos X (DRX), Ángulo de contacto (Hidrofilicidad de las fibras), Ensayos mecánicos de las membranas en estudio, Microscopía Electrónica de Transmisión (TEM), Microscopía de Fuerza Atómica (AFM). La liberación del principio activo se realizó en una solución salina amortiguada por fosfatos (PBS buffer) a $37^{\circ} \mathrm{C}$ y $\mathrm{pH}=7.4$. La cinética de liberación se analizó mediante el trazado de los datos acumulativos frente al tiempo. Este sistema fue capaz de liberar desde $65 \%$ a $85 \%$ de clorhidrato de tiamina en un periodo de $60 \mathrm{~h}$, aproximadamente, lo cual evidencia la potencialidad de estas membranas para liberar efectivamente a la vitamina $B_{1}$.

Palabras clave: clorhidrato de tiamina, Electrohilado, Liberación controlada, Policaprolactona, Quitosano.

\begin{abstract}
Currently there are significant research on the preparation of bioabsorbable porous membranes that allow the controlled release of drugs and vitamins. In this study it was proposed to prepare porous membranes from polycaprolactone (PCL) and chitosan (CS) under the electrospinning technique, applying different parameters in order to evaluate its internal characteristics and properties for a potential application as liberator of thiamine hydrochloride (vitamin $B_{1}$ ). Besides studying the in vitro release kinetics developed TC with membranes prepared. A polymer membrane was obtained from a solution of PCL/CS w/w (8:1) and PCL/CS w/w (10:1) with a load of TC regarding PCL w/w (20:1) dissolved in TFA/DCM v/v (80:20), with lows defects such as bulbs and uniform diameters. The fibers were characterized with support techniques of Scanning Electron Microscopy (SEM), Infrared spectroscopy (FTIR), Differential Scanning Calorimetry (DSC), Thermogravimetric Analysis (TGA), X-Ray Diffraction (XRD), contact angle (Hydrophilicity of the fibers), mechanical testing of the membranes in study, Transmission Electron Microscopy (TEM), Atomic Force Microscopy (AFM). The release of active substance is performed in a buffered saline by phosphates (PBS buffer) over $37^{\circ} \mathrm{C}$ and $\mathrm{pH}=7.4$. The release kinetics was analyzed by plotting cumulative data versus time. This system was able to release from $65 \%$ to $85 \%$ thiamine hydrochloride in a $60 \mathrm{~h}$, approximately, which shows the potential of these membranes to effectively release vitamin $B_{1}$.
\end{abstract}

Key words: Thiamin hydrochloride, Electrospinning, Controlled release, Polycaprolactone, Chitosan.

\section{Introducción}

La nanotecnología representa una frontera importante con potencial para avanzar significativamente en el campo de la ingeniería de tejidos [1,2]. La preparación y uso de membranas porosas basadas en nanofibras han cobrado interés recientemente para aplicaciones biomédicas, especialmente en la ingeniería de tejidos, cuyo objetivo es crear estructuras biodegradables y biocompatibles con propiedades mecánicas y biológicas similares a la matriz extracelular (ECM), entre varias técnicas de preparación de membranas porosas se presenta el electrohilado como una técnica con gran potencial [3].

El proceso de electrohilado, permite que una amplia gama de fármacos puedan ser directamente encapsulados dentro de la fase en masa de fibras a nanoescala disuelto o dispersado en el disolvente orgánico usado para electrohilado. La malla fibrosa resultante posee un período de tres dimensiones con una estructura porosa abierta y alta área superficial específica, proporcionando una condición ideal para la administración controlada de fármacos [5]. Hasta la fecha, el electrohilado se ha usado para la fabricación de andamios de numerosos polímeros biodegradables, tales como poli( $\varepsilon$-caprolactona) (PCL), poli(ácido láctico) (PLA), poli(ácido glicólico) (PGA), poli(lactida-co-glucósido) (PLGA) y poliuretano (PU) [4]. Además, las proteínas naturales también se han utilizado, incluyendo colágeno, elastina y gelatina.

Los polímeros naturales han sido de gran interés por su no toxicidad, compatibilidad con otros biopolímeros, la adhesión celular y la proliferación; como la quitina, quitosano y celulosa. Estos se mezclan a menudo con polímeros sintéticos porque poseen limitaciones como la baja estabilidad, la liberación de tóxicos y productos de degradación que pueden ser perjudiciales para las células, ya que la miscibilidad entre sus moléculas es un factor muy importante especialmente para las propiedades mecánicas de la mezcla $[6,7]$. 
Las fibras electrohiladas de PCL son estudiados para la ingeniería de tejidos por ser ventajosos, ya que el tamaño del poro se puede controlar fácilmente cambiando la densidad de la fibra en la unidad de área [8].

La poli( $\varepsilon$-caprolactona) (PCL) es un polímero semicristalino, biodegradable con buenas propiedades mecánicas, fácil de procesar, compatible tanto con tejidos duros como blandos y aceptado por la FDA. La PCL es útil en la producción de fibras electrohiladas que simulan la matriz extracelular. Sin embargo, su hidrofobicidad limita la adhesión y proliferación celular. Con la finalidad de modificar sus propiedades superficiales se mezcla con polímeros hidrofílicos materiales naturales que facilitan la adhesión celular, el incremento en las propiedades mecánicas y térmicas de las membranas basados en la PCL [3].

Recientes estudios indicaron el uso de la técnica de electrohilado para lograr la liberación controlada de un modelo hidrofílico de fármaco (ampicilina) presentando una baja compatibilidad con la policaprolactona (Sultanova et al. [9]). Otros autores evaluaron cómo las diferentes concentraciones de PCL y dipiridamo (DIP) con la técnica del electrohilado, afecta a las propiedades estructurales y físicas de las fibras (Repanas y Glasmacher [10]). De otro lado Irani et al. [11], evaluaron la carga y liberación de pequeñas moléculas y macromoléculas de fármacos en materiales compuestos de silicio poroso nanoestructurado y policaprolactona (PSI-PCL) prensadas, y su capacidad para soportar la unión de células de mamíferos y su crecimiento. De la misma manera otros estudios indican, que una mezcla de poli $(\varepsilon$ caprolactona) (PCL) y poli(óxido de etileno) (PEO) se electrohilaban para producir mallas fibrosas que podían liberar un fármaco proteico de una manera controlada. Estas mallas mostraron una buena estabilidad morfológica después de la incubación en la solución tampón, lo que resultó en la liberación controlada de lisozima durante un período prolongado con la reducción de ráfagas iniciales [5].

Varias fibras de PCL cargadas con fármaco preparadas a partir de solución, suspensión y emulsión mostraron que las fibras de PCL son una opción potencial de entrega de fármacos para cualquier tipo de medicamentos. Estas fibras también se pueden preparar después de la copolimerización con otros polímeros tales como PEG, quitosano o clorofilina [8].
El quitosano (CS) es un polisacárido, similar a la estructura de la celulosa. El grupo amino primario rinde propiedades especiales que hacen al CS muy útil en aplicaciones farmacéuticas. Comparado con muchos otros polímeros naturales, el quitosano tiene una carga positiva y es mucoadhesivo [12]. Por lo tanto, se utiliza ampliamente en aplicaciones de administración de fármacos. El quitosano se degrada bajo la acción de fermentos, es atóxico y fácilmente extraíble del organismo sin causar reacciones secundarias concurrentes. Posee propiedades antimicrobianas y absorbe los metales tóxicos como: mercurio, cadmio, plomo, etc. Además, tiene buena adhesión, capacidad de coagulación y actividad inmunoestimulante [13]. El quitosano es un polímero prometedor para la entrega de fármacos para el colon, ya que puede ser degradado por la flora bacteriana del colon y por su poder mucoadhesivo [14].

Varios estudios relacionados con el electrohilado de quitosano evaluaron el comportamiento de liberación de clorhidrato de tetraciclina cargado en un andamio antimicrobiano de quitosano/poli(ácido láctico) (Tet-CS/PLA) (Jiang et al. [15]). También, Rieger et al. [16], demostraron que las nanofibras de quitosano/CA/PEO pueden servir como vehículos de suministro de Cinamaldehido (CA) que potencialmente erradican las infecciones causadas por pseudomonas. Song et al. [17], prepararon una membrana electrohilada de quitosano/poli(óxido de etileno) (PEO) que contenía nanopartículas de plata como un vehículo de administración implantable para la liberación dual de iones de clorhexidina y plata. Este estudio se realizó para prevenir las infecciones percutáneas.

En general, todos los estudios anteriores han mostrado como se lograron preparar nanofibras por electrohilado de policaprolactona (PCL) y de quitosano (CS) de manera independiente, y la forma en que cada uno de ellos logró hacer la liberación de distintos tipos de fármacos. Sin embargo, ninguno de ellos muestra haber electrohilado PCL y CS de manera conjunta para la liberación de fármaco como el clorhidrato de tiamina (TC) por medio de un soporte obtenido por la técnica de electrohilado. Por tanto, el objetivo de este trabajo es estudiar la preparación de membranas a partir de diferentes concentraciones de PCL y CS con el disolvente mixto de ácido trifluoroacético/diclorometano (TFA/DCM) bajo 
diferentes parámetros de electrohilado, con el fin de observar las propiedades estructurales, térmicas y mecánicas de estas membranas, así como el estudio cinético de liberación del clorhidrato de tiamina, lo cual permitirá conocer la viabilidad de estas membranas para usarse como vehículos de liberación de la vitamina.

\section{Metodología}

La poli( $\varepsilon$-caprolactona) (PCL, peso molecular 80,000 Da), el quitosano (CS, bajo peso molecular 50,000 a 190,000 Da, grado de desacetilación 98\%), el clorhidrato de tiamina (TC) al 99\%, los solventes para la mezcla polimérica ácido trifluoroacético (TFA) al 99\%, diclorometano (DCM) al 99.8\% se obtuvieron de Sigma Aldrich.

\subsection{Preparación de la solución polimérica}

La mezcla polimérica se inició con la disolución del CS en TFA que duró aproximadamente de 3 a 5 horas, posterior a ésta se agregó la PCL se electrohiló a las 16 horas cuando se encontraba totalmente disuelta la mezcla polimérica. La fase I, se llevó a cabo con PCL/CS a una relación w/w A (8:1) y B (10:1) disueltos en TFA. La fase II, se llevó a cabo con carga de TC al 5\% concentración w/w respecto a $1 \mathrm{~g}$ de PCL, disueltos en TFA/DCM v/v (4:1), con PCL/CS a una concentración w/w C (8:1), su viscosidad fue de $142.3 \mathrm{cP}$ a una velocidad de 150 r.p.m. y D (10:1), su viscosidad fue de $75.33 \mathrm{cP} \mathrm{a}$ una velocidad de 150 r.p.m.

Para todos los tratamientos se usó el TFA teniendo en cuenta que la PCL tiene una fácil cristalización, lo que explica su limitada solubilidad en muchos disolventes que son capaces de disolver otras estructuras de poliéster amorfos. La cinética de degradación de la PCL es muy lenta, por lo que es muy conveniente para la aplicación de los sistemas de suministro de liberación lenta con cinética de largo plazo se extienda durante períodos superiores a 1 año. El TFA es un disolvente adecuado para disolver la PCL y es eficaz para la degradación de este [18, 19]. El TFA es un disolvente adecuado para electrohilar quitosano porque los grupos amino del quitosano pueden formar sales con TFA, capaz de destruir eficazmente las interacciones intermoleculares entre las moléculas de quitosano que facilitan electrohilado [20, 21]. El quitosano en su forma cristalina es normalmente insoluble en soluciones acuosas, su solubilización se alcanza debido a grupos amino libres protonables presentes en su estructura molecular, según el siguiente equilibrio (ver ecuación (2)) [22]:

$$
\text { Quito }-\mathrm{NH}_{2}+\mathrm{H}_{3} \mathrm{O}^{+} \longleftrightarrow \text { Quito }-\mathrm{NH}_{3}+\mathrm{H}_{2} \mathrm{O}
$$

La protonación de quitosano lo transforma en un polielectrolito en soluciones ácidas. La disolución del TFA con o sin DCM y CS produce residuos de sales debido a la alta solubilidad. Este tipo de sales son $-\mathrm{NH}_{3}^{+} \mathrm{CF}_{3} \mathrm{COO}^{-}$(sales trifluoroacetato de quitosano) [23, 24].

\subsection{Técnica de preparación de las membranas}

Para la fabricación de las membranas se usó un equipo de electrohilado conectado a una fuente de voltaje de alta tensión Glassman EH60, una bomba de inyección marca NE-300 TM y un colector plano de aluminio [19]. La solución se depositó en una jeringa con una aguja de acero inoxidable calibre 22 G, como capilar. Se probaron caudales de la solución polimérica desde 0.05 a $0.4 \mathrm{~mL} / \mathrm{h}$. El voltaje aplicado entre la aguja y el colector fueron desde 10 hasta $15 \mathrm{kV}$ y la distancia entre ellos se varió entre 8 y 15 $\mathrm{cm}$. El electrohilado se llevó a cabo a temperatura ambiente.

Tabla 1. Tratamientos sin Clorhidrato de Tiamina

\begin{tabular}{|c|c|c|c|c|c|}
\hline \multirow{3}{*}{$\begin{array}{l}\text { Tipo } \\
\text { de } \\
\text { trat. }\end{array}$} & \multirow{3}{*}{$\begin{array}{l}\text { Concent. } \\
\text { sln. } \\
\text { polim. } \\
\text { w/w }\end{array}$} & \multirow{3}{*}{ Ste. } & \multicolumn{3}{|c|}{ Parámetros } \\
\hline & & & Voltaje & Flujo & $\begin{array}{l}\text { Distancia } \\
\text { aguja- } \\
\text { colector }\end{array}$ \\
\hline & & & $\mathrm{kV}$ & $\mathrm{mL} / \mathrm{h}$ & $\mathrm{cm}$ \\
\hline \multirow{3}{*}{ A } & \multirow{3}{*}{$\begin{array}{l}\text { PCL/CS } \\
(8: 1)\end{array}$} & & 10 & 0.2 & 8 \\
\hline & & TFA & 10 & 0.2 & 10 \\
\hline & & & 13 & 0.1 & 10 \\
\hline \multirow{3}{*}{ B } & \multirow{3}{*}{$\begin{array}{l}\text { PCL/CS } \\
(10: 1)\end{array}$} & TFA & 15 & 0.05 & 10 \\
\hline & & /DCM & 15 & 0.2 & 13 \\
\hline & & & 15 & 0.05 & 15 \\
\hline
\end{tabular}

trat.: tratamiento; Concent. sln. polim.: concentración solución polimérica; ste: solvente

En la tabla 1 se presentan los diferentes tratamientos de acuerdo a los parámetros de la técnica de electrohilado que se usaron con PCL/CS a diferentes concentraciones, sin adicionar el TC. En la tabla 2 se puede observar los tratamientos que se usaron las mismas concentraciones de la tabla 1, pero ahora con 
la adición de TC y bajo otros parámetros de electrohilado. Se realizó estos dos grupos de tratamientos con el fin de determinar a cual concentración de PCL/CS y con cuales parámetros se logra obtener membranas con nanofibras definidas, con la menor cantidad de defectos y homogeniedad de las fibras para la distribución de la vitamina.

Tabla 2. Tratamientos con Clorhidrato de Tiamina

\begin{tabular}{|c|c|c|c|c|c|}
\hline \multirow{3}{*}{$\begin{array}{l}\text { Tipo } \\
\text { de } \\
\text { trat. }\end{array}$} & \multirow{3}{*}{$\begin{array}{l}\text { Concent. } \\
\text { sln. } \\
\text { polim. } \\
\text { w/w }\end{array}$} & \multirow{3}{*}{ Ste. } & \multicolumn{3}{|c|}{ Parámetros } \\
\hline & & & Voltaje & Flujo & $\begin{array}{l}\text { Distancia } \\
\text { aguja- } \\
\text { colector }\end{array}$ \\
\hline & & & $\mathrm{kV}$ & $\mathrm{mL} / \mathrm{h}$ & $\mathrm{cm}$ \\
\hline $\mathrm{C}$ & $\begin{array}{l}\text { PCL/CS } \\
(8: 1)\end{array}$ & TFA & 13 & 0.4 & 10 \\
\hline D & $\begin{array}{l}\text { PCL/CS } \\
(10: 1)\end{array}$ & /DCM & 15 & 0.3 & 15 \\
\hline
\end{tabular}

trat.: tratamiento; Concent. sln. polim.: concentración solución polimérica; ste: solvente

\subsection{Medición y caracterización}

Las características morfológicas de las membranas obtenidas por electrohilado se obtuvieron con la técnica Microscopia Electrónica de Barrido (SEM) de emisión de campo tipo Schottky (FE-SEM, siglas en inglés) JEOL Modelo JSM-7600F. La preparación de las muestras se realizó con un recubrimiento de una película de oro mediante pulverización catódica asistida por plasma para favorecer la conductividad de la muestra, el voltaje de operación para el haz de electrones fue de $15 \mathrm{kV}$. La distribución de diámetros, el diámetro promedio y el porcentaje de área porosa se calcularon con el software Image-J a partir de las micrografías obtenidas de 50 recuentos. El análisis químico se realizó por medio de espectroscopía infrarroja por transformada de Fourier (FTIR) un equipo FTIR-Thermo Scientific Nicolet 6700 y un sistema de reflexión total atenuada (ATR) ATRSmart Orbit, sobre un intervalo de número de onda entre 400 y $4000 \mathrm{~cm}^{-1}$. Las propiedades térmicas de las membranas se estudiaron por calorimetría diferencial de barrido (DSC, siglas en inglés) en un equipo DSC Q2000 TA Instruments, entre 0 y 250 ${ }^{\circ} \mathrm{C}$ a una rampa de calentamiento de $10{ }^{\circ} \mathrm{C} / \mathrm{min}$.

El comportamiento de la degradación y estabilidad térmica de cada una de las muestras se llevó a cabo con un analizador TGA Q 5000 TG (TA Instruments). Las muestras de aproximadamente $7 \mathrm{mg}$ fueron sometidas a calentamiento desde 25 a $800{ }^{\circ} \mathrm{C}$ a una rampa de $10{ }^{\circ} \mathrm{C} / \mathrm{min}$ bajo atmósfera de nitrógeno. Los patrones de difracción de rayos $\mathrm{X}$ fueron obtenidos usando el difractómetro SIEMENS D-500, utilizando la radiación de $\mathrm{Cu} \mathrm{K} \alpha(\lambda=0.1542(\AA)$. Se empleó un goniómetro Ramé-hart, inc. Modelo 100-07-00, ajustado con un sistema óptico, para observar la interacción del agua con la superficie de las membranas de PCL/CS con carga de TC, para determinar la hidrofilicidad o hidrofobicidad de las membranas se depositó una gota de agua sobre la membrana y se tomaron imágenes durante 2:40 min, de los cuales se eligieron 3 tiempos 1,90 y 150 segundos para medir los ángulos. Es sabido que el CS es más hidrofílico que la PCL, por lo que se consideró hacer los ensayos de ángulo de contacto con el fin de evaluar la humectabilidad en la superficie del andamio como posible resultado de la combinación de CS y PCL. Las propiedades mecánicas de las membranas, se realizaron con el fin de determinar las propiedades estructurales a las que estará sometido una membrana en el cuerpo humano cuando está liberando la vitamina. Este estudio se realizó con una máquina universal de pruebas mecánicas Instron $5500 \mathrm{R}$, con una celda de carga de $500 \mathrm{~N}$ y velocidad de deformación de $10 \mathrm{~mm} / \mathrm{min}$ a $25^{\circ} \mathrm{C}$. Con el fin de determinar la distribución del fármaco en las nanofibras fue visto por medio de la técnica de Microscopía Electrónica de Transmisión (TEM) con un microscopio JEOL JEM-1200EX. La topografía de la superficie de las membranas se caracterizó mediante Microscopía de Fuerza Atómica (AFM) utilizando un microscopio de sonda de barrido (SPM) JSPM4210 (JEOL Ltd) para evaluar la distribución de los polímeros con el fármaco en la nanofibra.

\subsection{Comportamiento de liberación de TC}

Se utilizó una celda de Franz [25] para analizar la cinética de permeación In vitro, mediante la liberación del fármaco en el sistema de estudio. El estudio se realizó en un sistema de 2 celdas para cada membrana electrohilada de PCL/CS con carga de TC, cada celda consta de un compartimento superior (donador), donde se coloca la membrana con un líquido que simulan los fluidos corporales, en este caso buffer PBS 0.1 M, separados por una membrana tipo GV $0.22 \mu \mathrm{m}$. El compartimento inferior posee un brazo de muestreo lateral por donde se toman alícuotas para analizar la concentración acumulada de los activos liberados. La celda posee 
una camisa externa que puede conectarse a un baño termostático con recirculación de manera de asegurar, una temperatura constante durante los ensayos de liberación. Esta temperatura se mantuvo a $37^{\circ} \mathrm{C}$. La agitación fue continua a 100 r.p.m. Cada 24 h, 3 $\mathrm{mL}$ de sobrenadante fue tomada desde el medio de liberación y se añadió inmediatamente $3 \mathrm{~mL}$ de PBS fresco ( $\mathrm{pH} 7.4$ a $37^{\circ} \mathrm{C}$ ) para mantener el volumen de la celda.

La concentración de la TC liberada se monitoreó en función del tiempo, midiendo sus absorbancias en un espectrofotómetro UV-Vis marca Ocean Optics, Inc., modelo DT1000CC-130. Las curvas de las concentraciones acumuladas de TC en función del tiempo se analizaron con base a la ecuación semiempírica del tipo ley de potencia (ecuación (2)), según Ritger y Peppas, 1987 [26]:

$$
\frac{M_{t}}{M_{\infty}}=k t^{n}
$$

en la ecuación, $\frac{M_{t}}{M_{\infty}}$ es el cociente de las concentraciones molares en el compartimiento receptor a tiempo t e $\infty$, respectivamente y representa la fracción de activo liberado al tiempo $t, k$ es una constante que incorpora la concentración del activo así como características geométricas y estructurales del dispositivo de liberación que incluyen el tipo de membrana utilizada y $\mathrm{n}$ es el exponente indicativo del mecanismo de liberación.

En la ecuación ecuación (2) cuando $n=0.5$ corresponde a la difusión fickiana (para intervalos de tiempo cortos). Valores de $\mathrm{n}$ superiores a 0.5 se asocian a un mecanismo de difusión anómalo (no fickiano). En particular, si $n=1$, la ecuación que se obtiene es la de cinética de orden cero, que Peppas considera un caso límite de transporte no-fickiano, denominado "transporte de Caso II" (Langer y Peppas, 1981). Esta cinética corresponde a la obtenida a partir de matrices poliméricas en las que el frente de hinchamiento del polímero avanza de forma constante. Valores de $n>1$ aparecen usualmente cuando el tiempo de liberación es muy elevado. Este tipo de mecanismo de difusión anómalo no fickiano lo denominan "transporte de Supercaso II". Por último, los valores de $n<0.5$, se asocian a la presencia de poros en la matriz polimérica, y la consiguiente difusión simultánea a través de la matriz hinchada y a través de los poros llenos de medio de disolución [27].

\section{Resultados y discusión}

\subsection{Análisis de la distribución de diámetros en las nanofibras y porosidad}

\subsubsection{Fase I. Membranas electrohiladas sin carga de TC}

En las figuras $1 \mathrm{~A}$, se puede observar la morfología por SEM de las membranas de nanofibras bajo diferentes tratamientos, siendo el más relevante la distancia entre la aguja-colector en el proceso de electrohilado. En la figura $1 \mathrm{~A}$ (i), se observa fibras interconectadas muy heterogéneas, esto pudo ser debido a que el solvente no se evaporó en el trayecto y se depositaron las fibras húmedas en el colector, presentan un diámetro promedio de $0.295 \mu \mathrm{m}$ y una desviación estándar de $0.127 \mu \mathrm{m}$. El porcentaje de porosidad de la muestra cargada con fármaco se encontró que era $51.1 \%$. En la figura $1 \mathrm{~A}$ (ii), se observa una estructura de fibras homogéneas muy interconectadas, con diámetro mayores (diámetro promedio de $0.552 \mu \mathrm{m}$ y una desviación estándar de $0.367 \mu \mathrm{m}$, el porcentaje de porosidad de la muestra cargada con fármaco se encontró que era $69.3 \%$ ), sin fusión entre las fibras, indicando con esto que la fibras se depositaron con menor humedad en el colector a comparación con la anterior, esto debido a que la distancia aumenta entre aguja y colector. En la figura $1 \mathrm{~A}$ (iii) al aumentar el voltaje a $13 \mathrm{kV}$ hay presencia de perlas,aguja y colector. Li y Wang [28], demostraron que la formación de perlas puede ser debido al bajo peso molecular/concentración y baja viscosidad, alta tensión superficial o baja densidad de carga. Podemos concluir que a bajas concentraciones y alta la fuerza eléctrica generada, hace que la solución solidifique el polímero de manera muy rápida y se acumule en forma de perlas o gotas dispersas a una de las fibras esencialmente libre de gotas. Esto ocurre debido a un insuficiente enmarañamiento de cadenas en la solución (entanglement) donde la concentración crítica inicial Ci está por debajo en la concentración [29].

En todas las figuras $1 \mathrm{~B}$ se aumentó el voltaje a Q $=15 \mathrm{kV}$ respecto a los tratamientos mostrado en las figuras $1 \mathrm{~A}$; en este caso se usó una concentración a (10:1), en general se aprecian fibras interconectadas y delgadas, no se observan perlas, en este tratamiento se aumenta la distancia aguja-colector y el flujo varía con cada distancia estudiada. En la figura 1 B (i), se 
aprecian fibras fusionadas con diámetros muy delgados, esto pudo ocurrir debido a que el solvente no se evaporó completamente en el trayecto, presentan un diámetro promedio de $0.138 \mu \mathrm{m}$ y una desviación estándar de $0.059 \mu \mathrm{m}$. El porcentaje de porosidad de la muestra cargada con fármaco se encontró que era $57 \%$. En la figura $1 \mathrm{~B}$ (ii), con un aumento de la distancia aguja-colector a $\mathrm{d}=13 \mathrm{~cm}$, se aprecian fibras electrohiladas con menor fusión entre ellas, presentan un diámetro promedio de $0.130 \mu \mathrm{m}$ y una desviación estándar de $0.046 \mu \mathrm{m}$. El porcentaje de porosidad de la muestra cargada con fármaco se encontró que era $78.4 \%$ lo que se podría concluir que el solvente no se evapora en totalidad pero da al andamio una mayor porosidad en comparación con las membranas de las figuras $1 \mathrm{~B}$ (i). Se observan mejor su homogeneidad de diámetro de las fibras. En la figura $1 \mathrm{~B}$ (iii), con el aumento de la distancia a $\mathrm{d}=$ $15 \mathrm{~cm}$ y con una disminución del flujo a $Q=0.05$ $\mathrm{mL} / \mathrm{h}$, se observan fibras interconectadas, esto pudo ser debido a que el solvente no se secó en el trayecto, se observa menor porosidad en la membrana en comparación con la figura $1 \mathrm{~B}$ (ii), presentan un diámetro promedio de $0.174 \mu \mathrm{m}$ y una desviación estándar de $0.067 \mu \mathrm{m}$. El porcentaje de porosidad de la muestra cargada con fármaco se encontró que era $56.7 \%$.

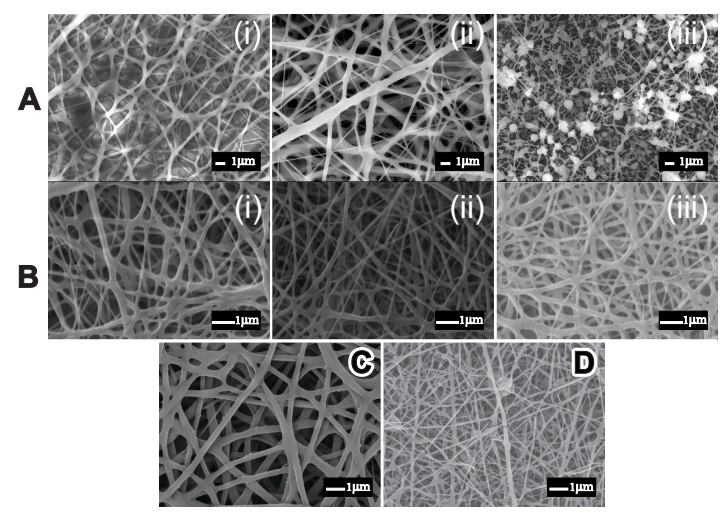

Figura 1. Micrografía SEM de electrohilado de PCL/CS disueltos en TFA, a una concentración w/w de: A (8:1) y B (10:1); PCL/CS disueltos en TFA/DCM con carga de TC, a una concentración w/w de: C (8:1) y D (10:1).

De esta primera fase, se determinó que el aumentar la concentración de la mezcla polimérica tratamiento B, se logran obtener fibras fusionadas con mejor homogeneidad del diámetro de las mismas, se obtuvo una mayor porosidad en las membranas en comparación con las fibras obtenidas del tratamiento A. También, se determinó que el aumento de la distancia aguja-colector permite un mayor secado y solidificación de las nanofibras.

\subsubsection{Fase II. Membranas electrohiladas con carga de $T C$}

En la figura $1 \mathrm{C}$ se puede observar las fibras de PCL/CS cuando se le agregó TC respecto a 1 $\mathrm{g}$ de PCL concentración w/w (20:1). La PCL/CS a una concentración w/w (8:1), se puede evidenciar que las fibras son homogéneas, distribuidas al azar con muy pocos defectos lo que indicaría que es una membrana que tiene características útiles para que la distribución del fármaco esté sobre la superficie y en el interior de la fibra, presentan un diámetro promedio de $0.282 \mu \mathrm{m}$ y una desviación estándar de 0.0803 $\mu \mathrm{m}$, la porosidad presentada en estas membranas fue de $66.34 \%$.

En la figura $1 \mathrm{D}$, se observa que las fibras están interconectadas posiblemente debido a que el solvente no se evaporó en el trayecto causando bulbos (material no electrohilado) y fusión entre ellas; presentan varios diámetros con un promedio de 0.104 $\mu \mathrm{m}$ y una desviación estándar de $0.040 \mu \mathrm{m}$; además los beads serán una característica muy importante como soporte útil en la retención de fármacos para una liberación sostenida y controlada del principio activo en su estudio de cinética de liberación. La porosidad presentada en estas membranas fue de $83.61 \%$.

De esta segunda fase se concluye que la membrana del tratamiento $\mathrm{C}$, presenta características potenciales para la liberación de fármaco, ya que ésta puede estar distribuida uniformemente en la fibra por presentar menos defectos y el tamaño de las fibras inferiores a $0.3 \mu \mathrm{m}$.

\subsection{Análisis de grupos funcionales en materiales y membranas por ATR-FTIR}

En la figura 2, se muestran los espectros de absorción ATR-FTIR de los espectros de PCL, CS, TC puros y las membranas pre y post-tratamiento; la asignación de bandas se resume en la tabla 3 . Se identifican fácilmente bandas intensas de la PCL como el enlace carbonilo $(\mathrm{C}=\mathrm{O})$ en modo de estiramiento a $1723 \mathrm{~cm}^{-1}$. La banda a $2863 \mathrm{~cm}^{-1}$ corresponde a un estiramiento simétrico del metileno $\left(\mathrm{CH}_{2}\right)$ y a $2942 \mathrm{~cm}^{-1}$ se encuentra la banda asimétrica de estiramiento del $\mathrm{CH}_{2}$. La banda a $1291 \mathrm{~cm}^{-1}$ se asigna a los enlaces $\mathrm{C}-\mathrm{O}$ y $\mathrm{C}-\mathrm{C}$ de la fase cristalina de la 
cadena principal de la PCL [20, 30]. Las bandas del CS son débiles debido a su baja concentración en las membranas.

El CS presenta picos característicos correspondientes al estiramiento de los grupos amino protonados (enlace sencillo $-\mathrm{NH}_{3}^{+}$) aproximadamente a 1644 y $1575 \mathrm{~cm}^{-1}$ [31].Se hacen evidentes las bandas de los grupos $\mathrm{OH}$ a $3356 \mathrm{~cm}^{-1}$ y N-H a $3288 \mathrm{~cm}^{-1}$, que resultan de la desacetilación a la que fue sometida la quitina. También se aprecian las bandas del grupo C-H a $2850 \mathrm{~cm}^{-1}$, grupo Piranósico a $1069 \mathrm{~cm}^{-1}$ y grupo C-O-C a $1021 \mathrm{~cm}^{-1}[32,33]$.

Tabla 3. Modos vibracionales de los grupos funcionales bandas de absorción de las membranas pre y postliberación a partir de la solución PCL/CS w/w (8:1) con carga de TC en TFA/DCM v/v (4:1).

\begin{tabular}{|c|c|c|c|c|c|c|}
\hline \multirow{2}{*}{$\begin{array}{l}\text { No. } \\
\text { onda } \\
{\left[\mathrm{cm}^{-1}\right]}\end{array}$} & \multirow{2}{*}{$\begin{array}{l}\text { Grupo } \\
\text { funcional }\end{array}$} & \multicolumn{5}{|c|}{ Muestra } \\
\hline & & $\overline{\mathrm{CS}}$ & $\overline{\mathrm{PCL}}$ & TC & $\begin{array}{l}\text { Memb. } \\
\text { pre-liber. }\end{array}$ & $\begin{array}{l}\text { Memb. } \\
\text { post- } \\
\text { liber. }\end{array}$ \\
\hline 3429 & Tensión $\mathrm{NH}_{2}$ & - & - & $\sqrt{ }$ & $\sqrt{ }$ & - \\
\hline 3288 & Tensión N-H & $\sqrt{ }$ & - & - & $\sqrt{ }$ & - \\
\hline 2942 & Tensión $\mathrm{CH}_{3}$ & - & - & $\sqrt{ }$ & $\sqrt{ }$ & - \\
\hline 2942 & $\begin{array}{l}\text { Estiramiento } \\
\text { asimétrico } \\
\mathrm{CH}_{2}\end{array}$ & - & $\sqrt{ }$ & - & $\sqrt{ }$ & $\sqrt{ }$ \\
\hline 2863 & $\begin{array}{l}\text { Estiramiento } \\
\text { simétrico } \\
\mathrm{CH}_{2}\end{array}$ & - & $\sqrt{ }$ & - & $\sqrt{ }$ & $\sqrt{ }$ \\
\hline 1723 & $\begin{array}{l}\text { Estiramiento } \\
\text { carbonil } \\
\mathrm{C}=\mathrm{O}\end{array}$ & - & $\sqrt{ }$ & - & $\sqrt{ }$ & $\sqrt{ }$ \\
\hline 1653 & $\begin{array}{l}\text { Flexión } \\
\mathrm{N}-\mathrm{H}_{3} \\
\end{array}$ & - & - & $\sqrt{ }$ & $\sqrt{ }$ & - \\
\hline 1600 & $\begin{array}{l}\text { Flexión } \mathrm{C}=\mathrm{O} \\
\text { y } \mathrm{C}=\mathrm{C}\end{array}$ & - & - & $\sqrt{ }$ & $\sqrt{ }$ & - \\
\hline 1539 & Tensión C=N & - & - & $\sqrt{ }$ & $\sqrt{ }$ & - \\
\hline 1313 & $\begin{array}{l}\text { Tensión } \\
\mathrm{N}-\mathrm{H}_{2}\end{array}$ & $\sqrt{ }$ & - & - & $\sqrt{ }$ & - \\
\hline 1163 & $\begin{array}{l}\text { Estiramiento } \\
\text { COC }\end{array}$ & - & $\sqrt{ }$ & - & $\sqrt{ }$ & $\sqrt{ }$ \\
\hline
\end{tabular}

En la figura 2 (b), se observa el espectro del clorhidrato de tiamina respecto a la membrana pre y post-liberación (ver tabla 3). El TC presenta un estiramiento del enlace $\mathrm{C}-\mathrm{OH}$ que se encuentra en 1039 $\mathrm{cm}^{-1}$ (alcohol primario). En la banda $1536 \mathrm{~cm}^{-1}$ se encuentra el tiazol con un doble enlace del $\mathrm{C}=\mathrm{N}$; en $1600 \mathrm{~cm}^{-1}$ se observa el enlace de la pirimidina, donde se aprecia un doble enlace entre $\mathrm{C}=\mathrm{C}$ y $\mathrm{C}=\mathrm{N}$. La banda del metilo se observa en $2942 \mathrm{~cm}^{-1}$ y en la banda $3429 \mathrm{~cm}^{-1}$ se encuentra un estiramiento del $\mathrm{NH}_{2}$ [34]. En conclusión, se observa que la intensidad de las bandas de absorción de la membrana pre-liberación confirma que la PCL es el polímero en mayor concentración y la vitamina $\mathrm{B}_{1}$ la de menor concentración. En la membrana post-liberación de TC, se identifica la liberación de la vitamina y se observa mayor concentración de PCL en él, lo que indica que si hubo liberación del TC. Las bandas del CS son débiles debido a su baja concentración en las membranas.

(a)

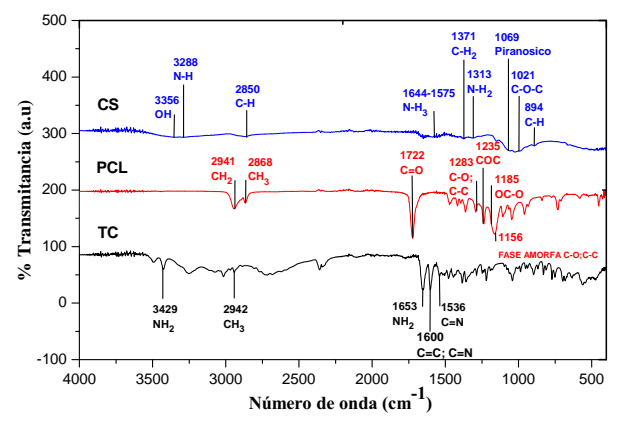

(b)

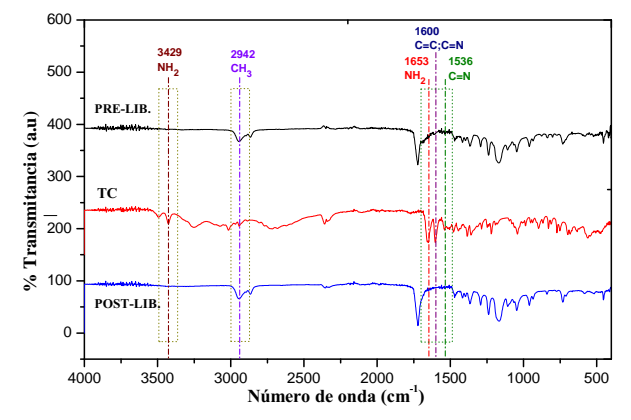

Figura 2. Espectros FTIR de: (a) reactivos puros y (b) membranas electrohiladas de PCL/CS pre y postliberación de TC.

El estudio espectroscópico muestra que no hay evidencias de reacción química entre los componentes que constituyen la membrana, no se observa ningún desplazamiento de la frecuencia en las bandas de los grupos funcionales característicos respecto a los correspondientes componentes puros, no hay una interacción mutua con formación de enlaces covalentes entre las cadenas de CS y PCL. Las interacciones posibles entre los componentes poliméricos incluyen enlaces de hidrógeno intermoleculares entre el átomo de oxígeno del grupo carbonilo de la PCL y el hidrógeno del grupo hidroxilo o ion amonio del CS, lo que resulta deseable en un andamio biodegradable para la liberación controlada de TC [35], porque estos materiales tienen la capacidad de ser compatibles con el tejido y de degradarse cierto tiempo después de ser implantados dando lugar a productos 
que no son tóxicos y pueden ser eliminados por el organismo o metabolizados por éste.

\subsection{Transiciones de fase por Temperatura de Transición por Calorimetría Diferencial de Barrido (DSC) y estabilidad térmica por Análisis Termogravimétrico (TGA)}

Se determinó la cristalinidad $\left(X_{c}\right)$ y temperatura de fusión $\left(T_{m}\right)$ de cada una de las muestras descritas en la tabla 4. Estos análisis se obtuvieron mediante el programa TA Universal Analysis. En la figura 3 (a), se observa las transiciones térmicas de los polímeros, la TC y las membranas de PCL/CS con carga de TC.

Tabla 4. Análisis térmico por DSC de muestras puras y cargadas con TC.

\begin{tabular}{|c|c|c|}
\hline Muestra & $X_{c}(\%)$ & $T_{m}(\check{\mathbf{r}} \mathbf{C})$ \\
\hline Policaprolactona (PCL) & $48.33^{*}$ & 62.08 \\
\hline Quitosano (CS) & - & -** \\
\hline Clorhidrato de Tiamina (TC) & 100 & 243.62 \\
\hline $\begin{array}{l}\text { Membrana de PCL/CS con car- } \\
\text { ga de TC }\end{array}$ & $48.95^{*}$ & 62.09 \\
\hline $\begin{array}{l}{ }^{*} \mathrm{X}_{c}=\Delta H_{m} / \Delta H_{m}^{\circ}, \text { con } \Delta H_{m}^{\circ}=1 \\
\text { de fusión de la PCL } 100 \% \text { crist }\end{array}$ & $\begin{array}{l}9.5 \mathrm{~J} / \mathrm{g}, \mathrm{e} \\
\text { lino [36] }\end{array}$ & \\
\hline
\end{tabular}

La policaprolactona (PCL) muestra un solo pico endotérmico correspondiente al punto de fusión $\left(T_{m}\right)$ a $62.08^{\circ} \mathrm{C}$ con una entalpía de $67.85 \mathrm{~J} / \mathrm{g}$, muy cercanos a los valores reportados por Murphy et al. [36], el análisis de quitosano (CS) mostró un primer pico endotérmico muy amplio en $82.48{ }^{\circ} \mathrm{C}$ debido a la eliminación de agua libre (desacetilación), tiene una entalpía de $273.3 \mathrm{~J} / \mathrm{g}$, García et al. [37] reportan esta eliminación de agua (ver figura 3 (c)); además, se detectó un pico exotérmico en $283.74{ }^{\circ} \mathrm{C}$ que podría ser debido a la descomposición de las cadenas de quitosano con una entalpía de $60.04 \mathrm{~J} / \mathrm{g}$.

La causa de la diferencia en la $T_{m}$ de estos polímeros puede ser debido a que las propiedades térmicas de quitosano dependen del grado de acetilación, cristalinidad y peso molecular medio [38, 39]. $\mathrm{La}$ $T_{m}$ del clorhidrato de tiamina (TC) está en 243.62 ${ }^{\circ} \mathrm{C}$ con una entalpía de $103.2 \mathrm{~J} / \mathrm{g}$, se observa una evaporación de agua en $82.50{ }^{\circ} \mathrm{C}$ y la membrana de PCL/CS con carga de TC presenta una $T_{m}$ de 62.09 ${ }^{\circ} \mathrm{C}$ con una entalpía de $84.84 \mathrm{~J} / \mathrm{g}$. En conclusión, se observa el pico endotérmico de la PCL más representativo en el andamio a diferencia del CS y TC, lo que hace su punto de fusión más característico en su análisis térmico de fusión [40].

(a)

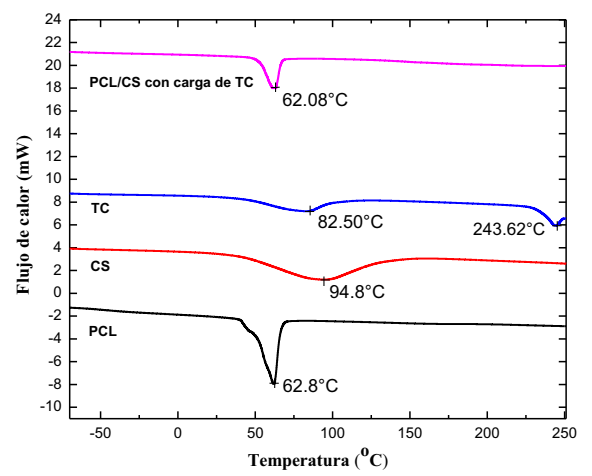

(b)

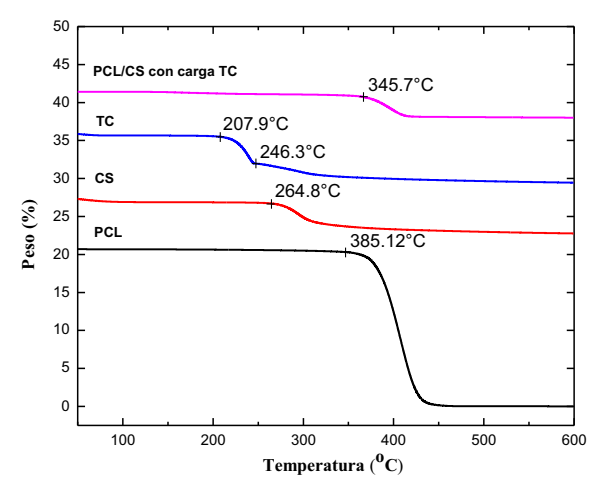

(c)

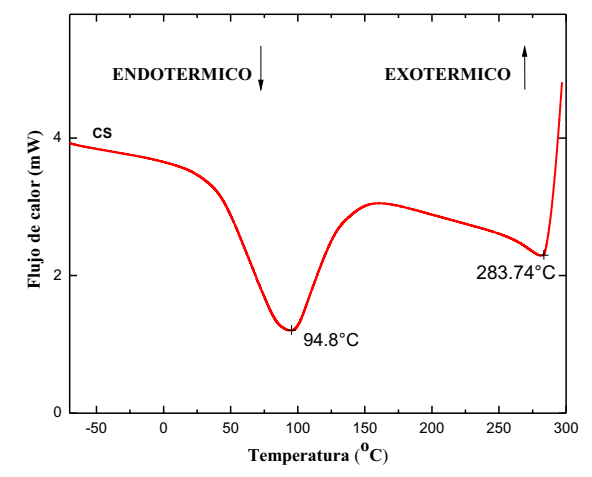

Figura 3. Termogramas de los materiales y la membrana PCL/CS w/w (8:1) con carga de TC en TFA/DCM v/v (4:1): (a) DSC, (b) TGA y (c) DSC del CS.

Debido a que las temperaturas de fusión de los componentes están por arriba de $\operatorname{los} 50^{\circ} \mathrm{C}$, se entiende que las membranas son dimensionalmente estables a la temperatura del cuerpo humano. las membranas también son térmicamente estables puesto que se no se degradan por efecto de la temperatura, estos se degradan por encima de los $200{ }^{\circ} \mathrm{C}$. 
En la figura 3 (b), se presentan los termogramas para determinar la degradación y estabilidad térmica de cada uno de los polímeros, el fármaco y la membrana de PCL/CS con carga de TC realizado entre 50 y $600{ }^{\circ} \mathrm{C}$. Se obtuvieron análisis termogravimétrico (TGA) mediante el programa TA Universal Analysis, donde se reconoce el comportamiento térmico de descomposición mostrando la pérdida de peso y la temperatura de descomposición de cada muestra.

La pérdida de peso de la membrana de PCL/CS con carga de TC se aprecia a una temperatura de $345.7{ }^{\circ} \mathrm{C}$ con una pérdida de masa que se relacionó con un descenso del $90.39 \%$, esto en comparación con la PCL por presentar mayor porcentaje de polímero en la disolución y que la policaprolactona mostró un punto a $385.12{ }^{\circ} \mathrm{C}$ que corresponde al cambio relevante en la rapidez de pérdida de masa y que se relacionó con un descenso del $97.82 \%$ en $40.21{ }^{\circ} \mathrm{C}$, visto como una caída casi vertical en el termograma TGA desde una temperatura de $385.12{ }^{\circ} \mathrm{C}$ a $425.33^{\circ} \mathrm{C}$ [36]. La pérdida de peso del quitosano (CS) se aprecia con un $56.86 \%$ a una temperatura de $264.8{ }^{\circ} \mathrm{C}$ debido a la presencia de un grupo amino libre en su estructura. El grupo funcional amino tiene la posibilidad de formar enlaces de hidrógeno intra e intermoleculares debido a su menor tamaño, produciendo entrecruzamiento en las cadenas poliméricas; además, su estructura molecular es más amorfa favoreciendo este tipo de interacción [41]. En la estabilidad térmica del clorhidrato de tiamina (TC) se observa dos etapas de pérdida de peso. La primera pérdida de peso es de $45.21 \%$ a los $207.9^{\circ} \mathrm{C}$, debido a la evaporación de agua. La segunda pérdida de peso es de $28.47 \%$ a $246.3{ }^{\circ} \mathrm{C}$ por la descomposición térmica de la TC.

\subsection{Difracción de Rayos $X$ (DRX)}

En la figura 4 (a), se observan los patrones de difracción de rayos-X de la policaprolactona, picos que se generan a los ángulos $19.58^{\circ}, 21.22^{\circ}$ y $23.68^{\circ}$. Lo cual implica que el material posee una estructura semicristalina, datos coincidentes con los autores Hernández M. et al [42]. (a)

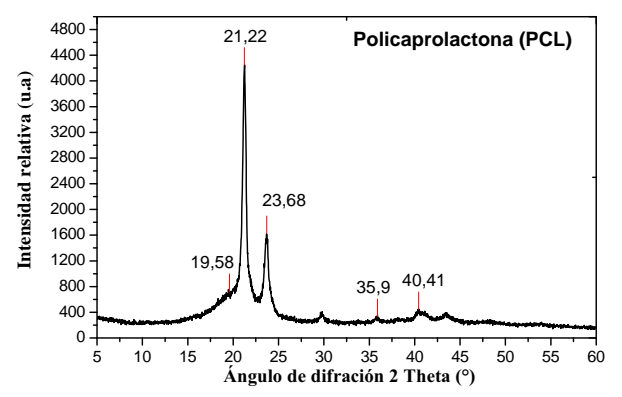

(b)

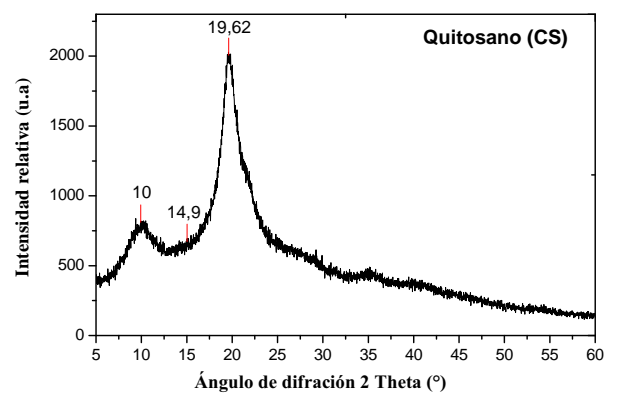

(c)

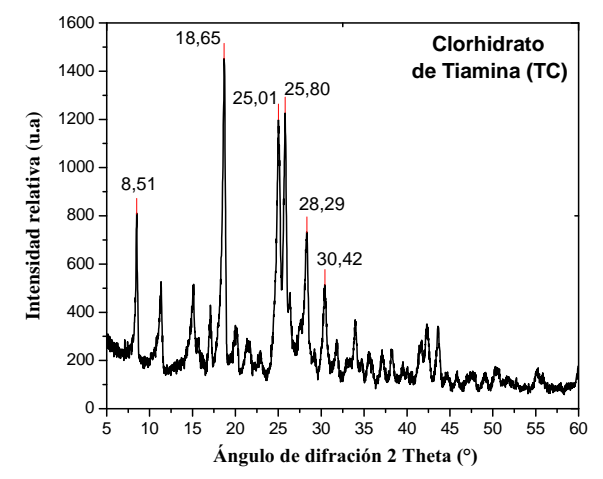

(d)

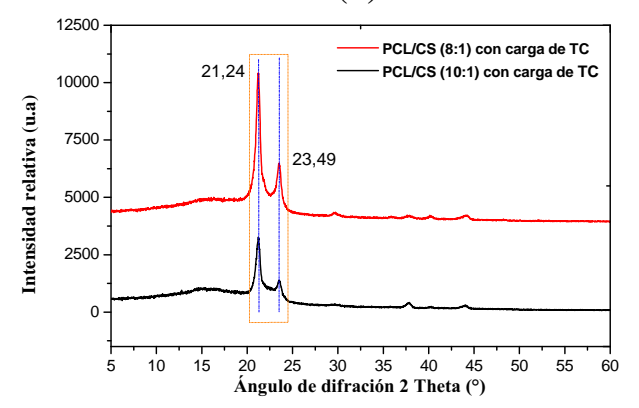

Figura 4. Difracción de rayos-X de: (a) Policaprolactona, (b) Quitosano, (c) Clorhidrato de Tiamina, (d) Membranas electrohiladas para estudios de la cinética de liberación.

El quitosano figura 4 (b) es cristalino y muestra polimorfismo, como se evidencia por sus patrones de difracción de rayos X. Su estructura es diferente de los alomorfos de la quitina y han sido refinadas las estructuras cristalinas de varias formas incluyendo formas anhidras e hidratadas, así como de varios 
tipos de sales. La forma hidratada del quitosano presenta dos flexiones, a $10^{\circ}$ y aproximadamente a $20^{\circ}$, la forma anhidra exhibe un pico en $2 \theta$ cerca de $15^{\circ}$. El CS presenta una fase cristalina y amorfa, donde las moléculas en estado sólido están organizadas en regiones cristalinas y coexisten con regiones amorfas, por lo que se demuestra la estabilidad de la estructura del biopolímero como resultado del tratamiento de desacetilación heterogénea $[33,42]$.

En la figura 4 (c) se observa los datos de difracción de rayos $X$ en el clorhidrato de tiamina, presenta un pico agudo característico a $2 \theta=8^{\circ}$, $18^{\circ}, 25^{\circ}, 26^{\circ}, 28^{\circ}, 30^{\circ}$ que corresponde a la reflexión plano del TC (www.rigaku.com/en/products/ xrd/miniflex/app006). Además de estos 6 picos hay algunos picos no identificados que aparecen en el patrón de DRX indicando que el TC es cristalino [43].

En la figura 4 (d) se observa las membranas electrohiladas con carga de TC presenta señales en el patrón de DRX, picos que corresponden a la PCL en $2 \theta=21^{\circ}$ y $23^{\circ}$, por ser el biopolímero utilizado en mayor concentración es el único que se observa. El patrón DRX de las membranas presentó una banda amplia sin la presencia de señales, entre $15-50^{\circ}(2$ $\theta$ ), lo cual está de acuerdo con la estructura semicristalina de este material. Además se observa dos leves picos entre 10 y $15^{\circ}$ que corresponde a la forma anhídrida del CS.

\section{5. Ángulo de contacto (Hidrofilicidad de las fibras)}

La determinación de ángulo de contacto teórico de la PCL fue de $115.64^{\circ} \pm 1.26^{\circ}$ [3]. Para la determinación del ángulo de contacto de las membranas de PCL/CS con carga de TC se depositó una gota de agua sobre la membrana y se tomaron imágenes durante 2:40 min, de los cuales se eligieron 3 tiempos (1, 90 y 150 segundos) para medir los ángulos. El quitosano es más hidrófilo que la PCL; por lo tanto, la adición de quitosano en PCL posiblemente cambiará la humectabilidad de la superficie de las membranas.

Teniendo en cuenta este punto, en la tabla 5 se encuentra los estudios de humectabilidad de 5 tratamientos por cada andamio de estudio donde se aprecia un incremento en la hidrofilicidad del $29.53 \%$ en el ángulo de contacto de la membrana PCL/CS w/w (8:1). Al inicio se obtuvo un ángulo de $50.48^{\circ}$ $\pm 2.02^{\circ}$, a los $90 \mathrm{~s}$ disminuyó a $30.76^{\circ} \pm 2.61^{\circ}$ y a $\operatorname{los} 150 \mathrm{~s}$, se redujo hasta $21.23^{\circ} \pm 2.69^{\circ}$, este valor se mantuvo constante después de dicho tiempo, y la gota se extendió sobre la membrana polimérica. $\mathrm{La}$ hidrofilicidad de la membrana polimérica permite tener una biodegradación más rápida como sistema portador de fármacos y su hidrólisis será mucho más rápida lo que indica que su eliminación en el cuerpo humano será totalmente posterior a la liberación del principio activo. En el ángulo de contacto de la membrana de PCL/ CS w/w (10:1), se observa un incremento del $37.41 \%$ en la hidrofilicidad, respecto al andamio de PCL/CS w/w (8:1). Al inicio se tenía un ángulo de $42.83^{\circ} \pm 3.39^{\circ}$, a los $90 \mathrm{~s}$ aumentó a $69.00^{\circ} \pm 2.49^{\circ}$ y a los $150 \mathrm{~s}$ se redujo hasta $65.22^{\circ} \pm$ $2.39^{\circ}$, este valor se mantuvo constante después de dicho tiempo y la gota se extendió sobre la membrana polimérica.

Tabla 5. Resultados de las mediciones de ángulo de contacto estático del agua de las membranas electrohilados de PCL/CS (8:1) Y (10:1) con carga de TC.

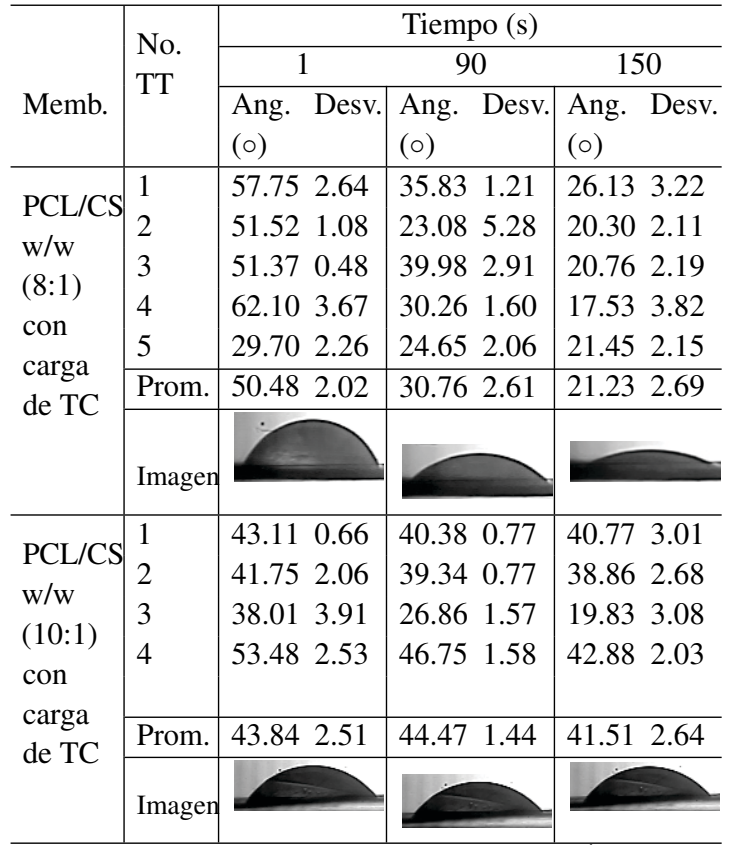

Memb.: Membrana; TT: Tratamiento; Ang.: Ángulo; Desv.: Desviación estándar; Prom.: Promedio.

Se concluye que las fibras más finas producirán un área de contacto líquido-sólido más pequeño y aumenta el área de contacto aire-líquido cuando se coloca una gota de agua sobre la superficie de la membrana, lo que lleva a un ángulo de contacto superior (superficie hidrofóbica), esto ocurre con la membrana de PCL/CS (10:1) que presenta un 
diámetro promedio de las fibras de $0.104 \mu \mathrm{m}$. Además, la composición y el diámetro de la fibra en conjunto determinan los ángulos de contacto de la membrana polimérica debido a la naturaleza de los polímeros naturales y sintéticos. En la membrana PCL/CS (8:1), el promedio de los diámetros de las fibras fue de $0.317 \mu \mathrm{m}$, un diámetro de fibra mayor a la membrana de PCL/ CS (10:1), por lo tanto su ángulo de contacto fue menor (superficie hidrofílica) debido a que esta membrana tenía mayor concentración de quitosano (polímero hidrofílico).

En la figura 5 se muestra las mediciones de ángulo de contacto para las diferentes membranas cargadas de TC, donde se hace evidente la disminución del ángulo de contacto concluyendo que la mezcla de la PCL con biopolímeros hidrófilos, mejora las propiedades de las membranas poliméricas como resistencia, alta porosidad y bioactividad para facilitar la adhesión celular y su fácil degradación dentro del organismo como lo reportan Barrera y Tan et. al $[3,44]$.

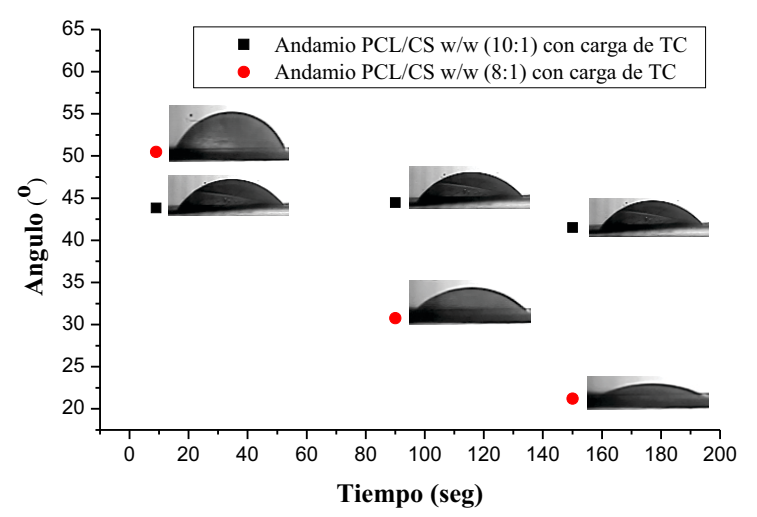

Figura 5. Medición de Ángulo de contacto vs Tiempo para las membranas electrohiladas de PCL/CS w/w (8:1) y $(10: 1)$.

\subsection{Ensayos mecánicos de las membranas en estudio}

En la figura 6 se observa los ensayos mecánicos donde se determinó que la membrana de PCL/CS w/w (8:1) con carga de TC presentó un valor de esfuerzo a la tensión de $0.63 \mathrm{MPa}$, un módulo de Young de 5.55 MPa y una elongación a la ruptura de $78.7 \%$ (ver tabla 6) en comparación de la membrana de PCL/CS w/w (10:1) con carga de TC que presentó una disminución del valor de esfuerzo a la tensión de $0.50 \mathrm{MPa}$, un módulo de Young de 1.86 MPa y una elongación a la ruptura de $221.4 \%$; donde la elongación a la ruptura aumenta en la membrana de PCL/CS w/w (10:1) con carga de TC debido al aumento de su peso molecular y los defectos de las fibras como bulbos y diámetros menores entre 0.104 $\pm 0.044 \mu \mathrm{m}$ que componen la membrana en comparación del diámetro de las fibras homogéneas de la membrana PCL/CS w/w (8:1) que estuvieron entre $0.282 \pm 0.138 \mu \mathrm{m}$ (ver figura $1 \mathrm{D}$ ).

(a)

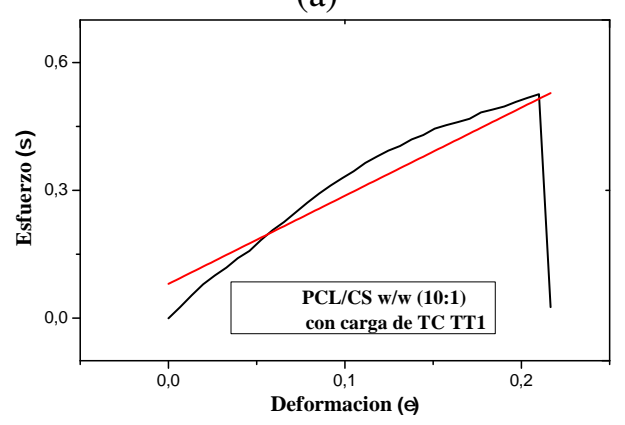

(b)

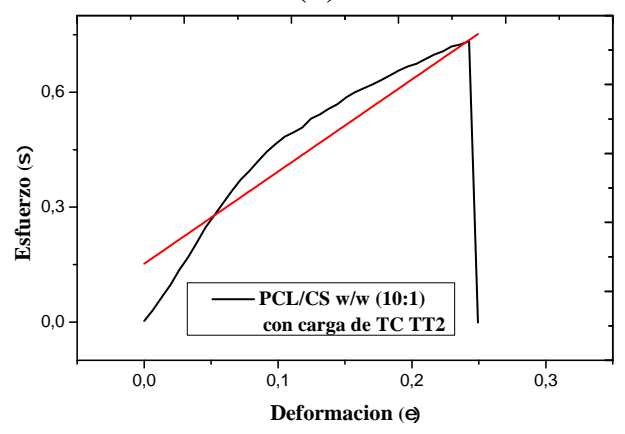

(c)

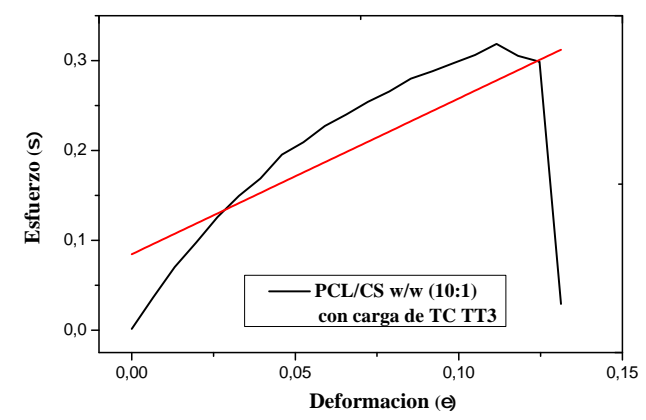

(d)

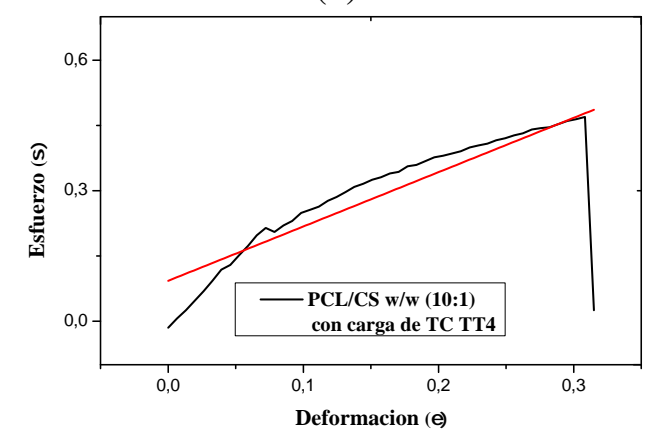

(e) 


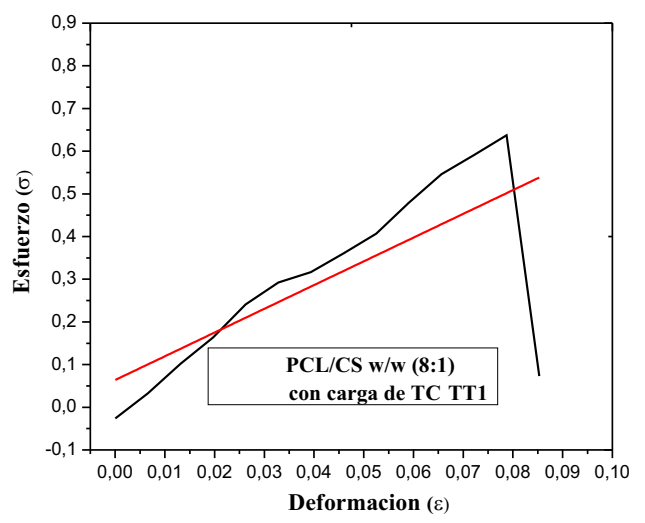

Figura 6. Curvas de tensión-deformación de las membranas electrohiladas de: PCL/CS w/w (10:1) con carga de TC (a) TT1, (b) TT2, (c) TT3 (d) TT4 y (e) PCL/CS w/w (8:1) con carga de TC TT1.

Tabla 6. Pruebas de tensión de las membranas electrohilados de PCL/CS w/w (8:1) y (10:1)

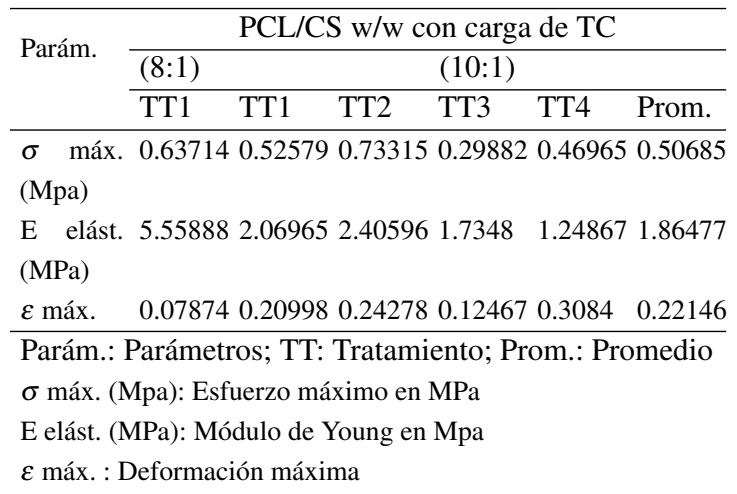

Los resultados dependen de la composición del material, de imperfecciones microscópicas, de la manera en que esté fabricado, de la velocidad de carga y de la temperatura durante la prueba $[45,46]$.

Barrera [3], reporta los valores de esfuerzo a la tensión de las membranas de PCL que se encuentra alrededor de $3 \mathrm{MPa}$, con elongación a la ruptura de $170 \%$ aproximadamente. Se concluye que la mezcla de polímeros naturales y sintéticos mejoran las propiedades mecánicas de los polímeros puros; además, que las fibras homogéneas con mínimos defectos tienen mayor esfuerzo a la tensión como es la membrana de PCL/CS w/w (8:1) en comparación de la membrana de PCL/CS w/w (10:1) que presenta menor esfuerzo a la tensión que puede ser debido a sus fibras heterogéneas y diámetros menores.

\subsection{Microscopía electrónica de transmisión (TEM) y Microscopía de Fuerza Atómica (AFM)}

Para evaluar la morfología y la dispersabilidad de TC en la nanofibra con PCL y CS se utilizó la microscopía electrónica de transmisión (TEM). En la figura 7 (a,b), se observa que el haz de electrones incidente atravesó la muestra permitiendo ver la sombra de detalles finos como es el fármaco (compuesto orgánico que se mezcla en la solución polimérica) dentro de las fibras de PCL, esto indica que la vitamina $B_{1}$ se encuentra distribuida en la membrana polimérica.

Las imágenes obtenidas por AFM (figura 7 (c,d)), muestran que las partículas orgánicas se encuentran superficialmente en las membranas poliméricas obtenidas por solución nanométrica. En la figura 7 (c) se observa la estructura coraza/núcleo (core/shell) donde en el interior de la fibra (núcleo) el CS con fármaco se deposita en forma de fibra, se comparó con el estudio hecho por Gómez et al. [47]. En la figura 7 (d) las fibras presentan incrustaciones de CS con fármaco sobre la superficie (coraza) esto se pudo haber dado debido a que la PCL es hidrofóbica y el CS es hidrofílico y su inmiscibilidad hace que el polímero de CS con TC se adhiera a la superficie de la fibra en forma de incrustaciones. El TC se distribuye en las nanofibras, tanto en su interior como en su superficie mezclándose con la PCL y CS [3, 48];

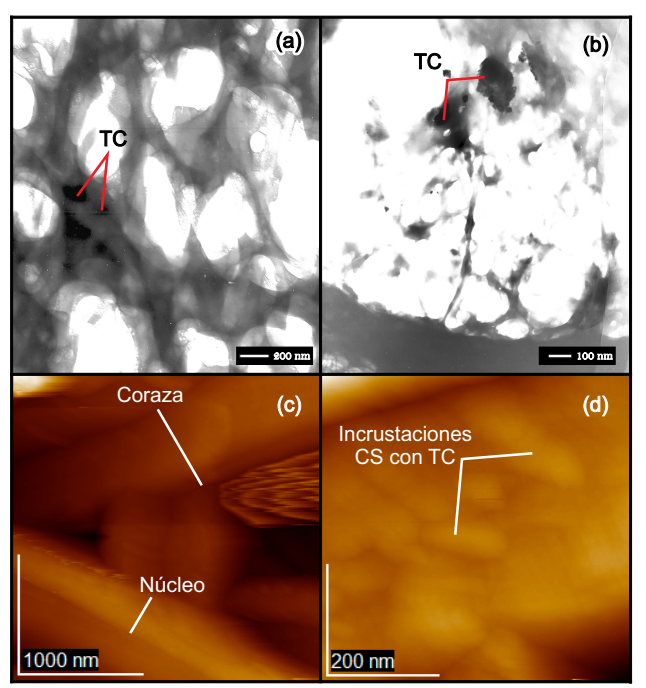

Figura 7. Microestructura de las fibras obtenidas por electrohilado de los polímeros de PCL/CS a una concentración w/w (8:1) disueltos en TFA/DCM a una concentración v/v (80:20) con una carga del 5\% w/w de TC respecto a $1 \mathrm{~g}$ de PCL $(\mathrm{a}, \mathrm{b})$ TEM y $(\mathrm{c}, \mathrm{d})$ AFM. 
(a)

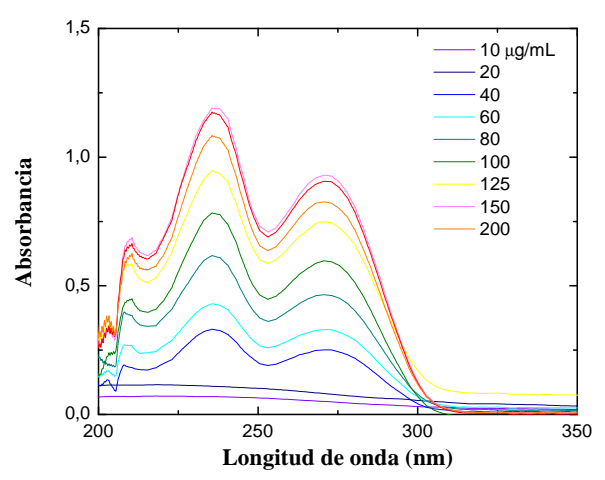

(b)

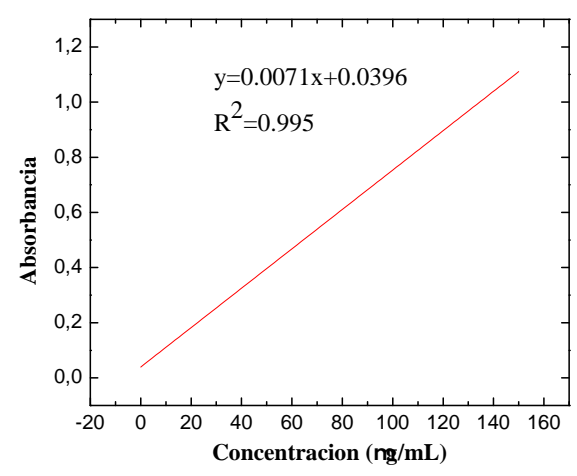

(c)

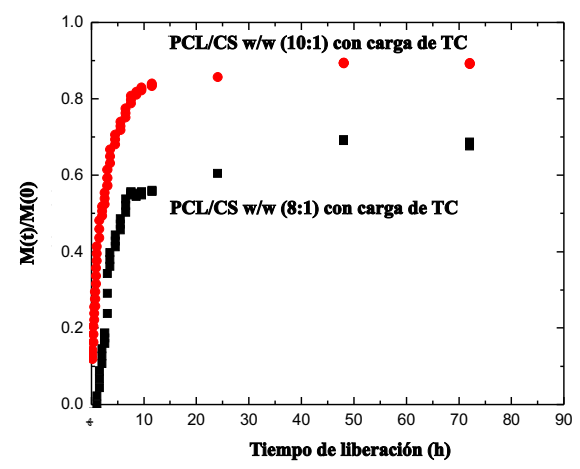

Figura 8. (a) Curvas de absorbancia de TC en solución buffer PBS al 0.1 M, (b) Curva de calibración empleada en los estudios de liberación de TC a $\lambda=235.56 \mathrm{~nm}$ y (c) Curvas de liberación de TC para las membranas de PCL/CS w/w (8:1) y (10:1), respectivamente.

\subsection{Cinética de liberación del Clorhidrato de Tiamina (Vitamina $B_{1}$ )}

En la figura 8 se muestran las curvas de absorbancia, calibración y liberación de TC de las membranas de PCL/CS. En la figura 8 (a) se observa que el incremento en la concentración del fármaco de clorhidrato de tiamina tiene el efecto de aumentar el valor de la absorbancia. En la figura 8 (b), se obtuvo una respuesta lineal con un coeficiente de correla- ción $>0.995$ en un intervalo de concentraciones de $5-160 \mu \mathrm{g} / \mathrm{mL}$.

En la figura 8 (c) se muestran las curvas de liberación de TC en función del tiempo para las dos membranas con concentraciones de PCL/CS (8:1) y (10:1). Se observa que la cinética de liberación del principio activo es similar en ambos casos; a las 15 horas se alcanza una liberación sostenida del TC, que se mantiene por lo menos $60 \mathrm{~h}$. Sin embargo, la membrana de PCL/CS w/w (10:1) libera el $85 \%$ de la vitamina en tanto que el PCL/CS w/w (8:1) solo libera el $65 \%$. Estos resultados indican que la membrana electrohilada de PCL/CS w/w (8:1) disueltos en TFA/DCM v/v (80:20) con una carga de TC respecto a la PCL w/w (20:1), (ver figura $1 \mathrm{D})$, es una membrana adecuada para una liberación controlada de vitamina, por sus fibras homogéneas, con mínimos defectos y bulbos, cargadas tanto en su interior como exterior por el TC a diferencia de la membrana de PCL/CS a una concentración w/w (10:1) (ver figura $1 \mathrm{C}$ ), fibras no homogéneas, beads y diámetros de fibras menores donde su área superficial es mayor y su cinética de liberación es más rápida.

En la figura 9 se observa el perfil de liberación del TC a las concentraciones establecidas para el estudio de liberación. En la figura 9 (a) fase I se observa que a tiempo de 3.5 horas (valor del tiempo en horas en la figura 9 (a) y (c) de 0 - 1.3) los valores de $n$ calculados para las formulaciones que contienen TC son cercanos a 0.5 , a medida que aumenta el contenido de PCL figura 9 (b), en las dos formulaciones con igual contenido de CS se produce un aumento de $n$, lo que evidencia que la liberación del clorhidrato de tiamina en la primera hora depende de un proceso de difusión a través de la matriz polimérica hinchada y a través de los poros formados en el biomaterial una vez que este entra en contacto con la disolución buffer de fosfato, obteniéndose en las dos formulaciones valores de $\mathrm{n}$ entre 0.37107 y 0.42066 (ver tabla 10), que corresponde a la fracción de TC que está ocluida en el material, pero muy próxima de la superficie. 


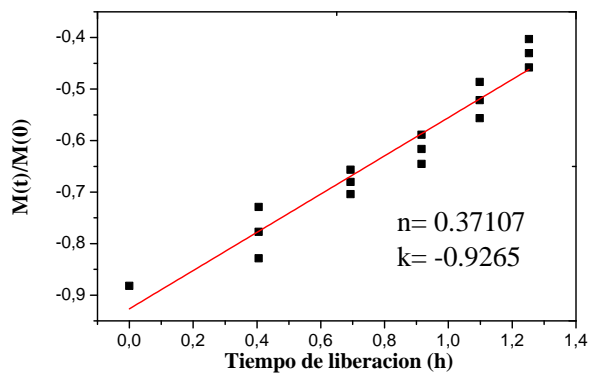

(b)

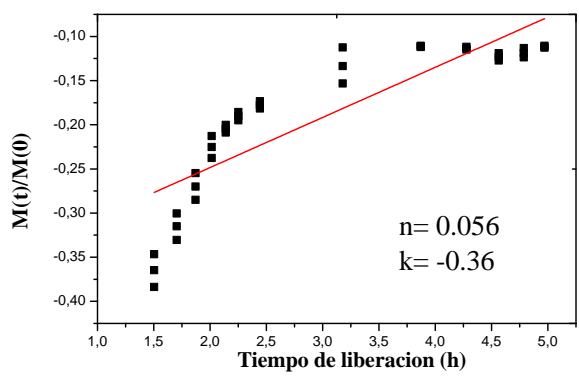

(c)

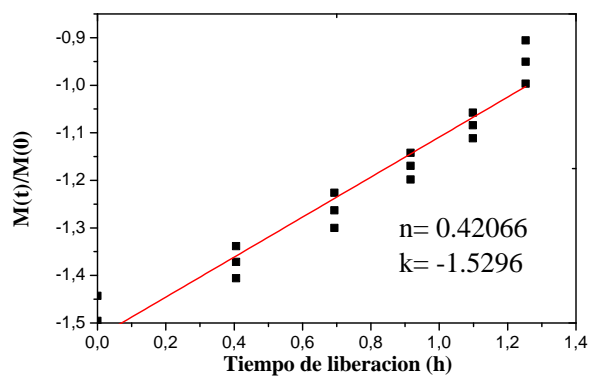

(d)

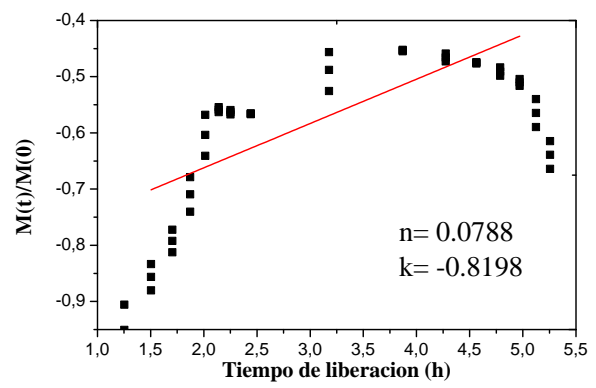

Figura 9. Perfil de liberación del clorhidrato de tiamina (a, b) PCL/CS w/w (8:1), (c, d) PCL/CS w/w (10:1).

En las siguientes horas la liberación de TC va a depender básicamente de lo que pueda avanzar frente al hinchamiento y el proceso de difusión se hace más lento, debido a que el TC debe recorrer un mayor camino para llegar al exterior. Cuando el medio externo penetra a la membrana, el polímero que inicialmente presenta un estado vítreo, se hincha y su temperatura de transición vítrea puede alcanzar valores inferiores a la temperatura del medio que lo rodea, pasando a un estado tipo elastomérico. En estas condiciones, el soluto difunde desde las regiones hinchadas al medio externo y su liberación está controlada por la velocidad de desplazamiento y posición de la interfase vítrea/elástica.

En la figura 9 (b) y (d) fase II se aprecia una disminución del valor de $n$ en el tiempo, entre 0.056 y 0.0788 (ver tabla 10) confirmándose de esta forma que la matriz polimérica PCL/CS es la encargada de controlar el proceso de liberación hasta 192 horas (valor del tiempo en horas en la figura 9 (a) y (c) de 1.5 - 5), ya que el TC liberado sigue un mecanismo de difusión Fickian a través de la matriz polimérica.

Figura 10. Coeficiente de difusión (n) obtenido de la ecuación de Ritger y Peppas en diferentes instantes de tiempo.

\begin{tabular}{|c|c|c|c|c|c|c|}
\hline \multirow[b]{2}{*}{ Fase Fig } & \multirow{2}{*}{$\begin{array}{l}\text { Tiempo } \\
\text { (h) }\end{array}$} & \multicolumn{2}{|c|}{ PCL/CS (8:1) } & \multicolumn{3}{|c|}{ PCL/CS (10:1) } \\
\hline & & $\mathrm{n}$ & $\mathrm{k}$ & гig & $\mathrm{n}$ & $\mathrm{k}$ \\
\hline $\begin{array}{l}\text { Fase } \\
I^{\text {(a) }}\end{array}$ & $\begin{array}{l}1-3.5 \\
(0-1.3)\end{array}$ & 0.37 & -0.92 & (c) & 0.42 & -1.52 \\
\hline $\begin{array}{l}\text { Fase } \\
\text { II (b) }\end{array}$ & $\begin{array}{l}4.5-192 \\
(1.5-5)\end{array}$ & 0.056 & -0.36 & (d) & 0.788 & -0.82 \\
\hline
\end{tabular}

En la figura 11 se observa las micrografías de degradación que tuvo las membranas poliméricas posteriores a 9 días en PBS. Las nanofibras se hinchan por la disolución en PBS (solución hidrófila) y la hidrólisis de los polímeros, formando una membrana irregular con muchos agujeros; también hay ruptura y disminución del diámetro de la fibra como se observa en la figura 11 (a), y cambios en la morfología de las fibras como hinchamiento por la hidrólisis, figura 11 (b).

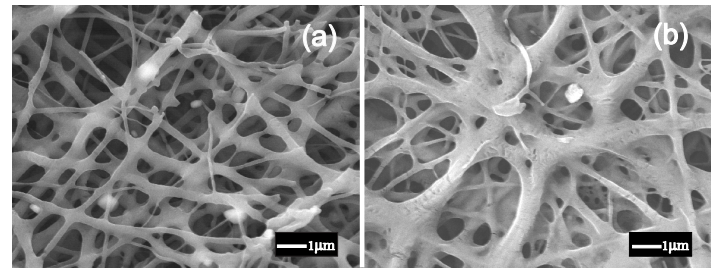

Figura 11. Micrografía SEM del estudio post-liberación de las membranas disueltos en PBS posterior a los 9 días: (a) PCL/CS w/w (8:1) y (b) PCL/CS w/w (10:1).

La hidrólisis es una reacción bimolecular en la que el agua y el grupo funcional que posee el enlace lábil están involucrados. El proceso de degradación consiste en dos etapas: primero, comienza una rotura aleatoria de enlaces éster, lo que conduce a una disminución en las propiedades mecánicas y reducción 
de la masa molecular del polímero. En la segunda etapa, existe un mayor desarrollo de rotura en los enlaces éster, lo que propicia una disminución de tamaño en las cadenas moleculares; provocando pérdidas de masa. Mediante la introducción de un segundo polímero en la solución polimérica, muchas de las propiedades de la mezcla polimérica pueden ser influenciadas, tales como cristalinidad, la temperatura de transición vítrea o el tiempo de degradación. Los polímeros hidrófilos ocupan grandes cantidades de agua, esto provoca un aumento en sus tasas de degradación correspondientes $[49,50]$.

\section{Conclusiones}

Se concluyó que los biopolímeros la PCL y CS usados en este estudio con propiedades físico químicas diferentes permiten ser mezclados con el TC a partir de disolventes orgánicos permitiendo su miscibilidad y biocompatibilidad bajo los análisis de FTIR. Esta mezcla polimérica mejora las propiedades de las membranas como su resistencia mecánica por medio de la técnica de electrohilado facilitando la adhesión celular y su biodegradación en el organismo para una liberación controlada de fármacos, esta técnica no genera cambios químicos en los componentes, lo cual indicaría que se presenta solo cambios físicos.

En este estudio se consiguió electrohilar la mezcla de PCL y CS con bajos voltajes y distancias cortas entre aguja-colector lo que generaría unos parámetros nuevos en la fabricación de membranas poliméricas para la liberación controlada de fármacos. Las concentraciones óptimas en el electrohilado con las cuales se obtuvo una disolución homogénea con alto coeficiente dieléctrico para la fabricación de membranas poliméricas fueron: PCL/CS w/w (8:1) con una carga de TC respecto a la PCL w/w (20:1) en una mezcla de disolventes TFA/DCM v/v (80:20) para obtener membranas con nanofibras homogéneas, mínimos defectos, sin bulbos de PCL/CS y alta capacidad de liberación de un $65 \%$, bajo los parámetros de electrohilado de: flujo de inyección de $0.4 \mathrm{~mL} / \mathrm{h}$, voltaje de $13 \mathrm{kV}$ y distancia aguja-colector de $10 \mathrm{~cm}$. En el tratamiento de PCL/CS w/w (10:1) se comprueba que la vitamina fue liberada hasta un $85 \%$ en 60 horas, lo que indica que fue más rápida la liberación en comparación con el tratamiento de PCL/CS w/w (8:1) debido a los defectos como bulbos y diámetros menores. En las dos formulaciones estudiadas el proceso de difusión cumple con la ley de Fick y el TC difunde a través de la matriz polimérica hinchada y los poros formados en el biomaterial.

\section{Agradecimientos}

Este trabajo fue apoyado y financiado por el convenio PAPIIT-UNAM IN 108116 y la Universidad Pedagógica y Tecnológica de Colombia (UPTC).

\section{Referencias}

[1] G. G. Walmsley, A. McArdle, R. Tevlin, A. Momeni, D. Atashroo, M. S. Hu, A. H. Feroze, V. W. Wong, P. H. Lorenz, M. T. Longaker, and D. C. Wan, "Nanotechnology in bone tissue engineering", Nanomedicine: Nanotechnology, Biology and Medicine, vol. 11, pp. 1253-1263, 7, 2015.

[2] A. Kumari, S. K. Yadav, and S. C. Yadav, "Biodegradable polymeric nanoparticles based drug delivery systems", Colloids and Surfaces B: Biointerfaces, vol. 75, pp. 1-18, 2010.

[3] S. A. Barrera, "Obtención de nanofibras modificadas de Poli( $\varepsilon$-caprolactona) por electrohilado para aplicaciones biomédicas", Instituto de Investigaciones en Materiales. Universidad Nacional Autónoma de México, 2014.

[4] M. E. Pérez, D. M. Ruiz, M. Schneider, J. C. Autino, G. Romanelli, "La química verde como fuente de nuevos compuestos para el control de plagas agrícolas", Ciencia en Desarrollo, vol. 4, no.2, pp. 83-91, 2013.

[5] T. G. L. Kim, Doo Sung; Park, Tae Gwan, "Controlled protein release from electrospun biodegradable fiber mesh composed of poly $(\varepsilon$ caprolactone) and poly(ethylene oxide)", International Journal of Pharmaceutics, vol. 338, 2007.

[6] K. T. Shalumon, K. H. Anulekha, C. M. Girish, R. Prasanth, S. V. Nair, and R. Jayakumar, "Single step electrospinning of chitosan/poly (caprolactone) nanofibers using formic acid/acetone solvent mixture", Carbohydrate Polymers, vol. 80, pp. 413-419, 2010.

[7] L. M. Moreno, E. Muñoz Prieto, H. Casanova, "Flocculation with Chitosan of Microalgae 
Native of the Colombian Plateau", Ciencia en Desarrollo, vol. 6, no.1, pp. 25-32, 2015.

[8] T. K. Dash and V. B. Konkimalla, "Poly- $\varepsilon-$ caprolactone based formulations for drug delivery and tissue engineering: A review", Journal of Controlled Release, vol. 158, pp. 15-33, 2012.

[9] Z. Sultanova, G. Kaleli, G. Kabay, and M. Mutlu, "Controlled Release of a Hydrophilic Drug from Coaxially Electrospun Polycaprolactone Nanofibers", International Journal of Pharmaceutics, 2016.

[10] A. Repanas and B. Glasmacher, "Dipyridamole embedded in Polycaprolactone fibers prepared by coaxial electrospinning as a novel drug delivery system", Journal of Drug Delivery Science and Technology, vol. 29, pp. 132-142, 2015.

[11] Y. D. Irani, Y. Tian, M. Wang, S. Klebe, S. J. McInnes, N. H. Voelcker, J. L. Coffer, and K. A. Williams, "A novel pressed porous siliconpolycaprolactone composite as a dual-purpose implant for the delivery of cells and drugs to the eye", Experimental eye research, vol. 139, pp. 123-131, 2015.

[12] E. Muñoz Prieto, J. Palacios Alquisira, C. Rius Alonso, "Microwave and Ultrasound Activation Effect on Cationization of Corn and Potato Starches", Ciencia en Desarrollo, vol. 4, no. 1, pp. 151-173, 2012.

[13] S. A. Agnihotri, N. N. Mallikarjuna, and T. M. Aminabhavi, "Recent advances on chitosanbased micro- and nanoparticles in drug delivery", Journal of Controlled Release, vol. 100, pp. 5-28, 2004.

[14] H. Zhang, I. A. Alsarra, and S. H. Neau, "An in vitro evaluation of a chitosan-containing multiparticulate system for macromolecule delivery to the colon", International Journal of Pharmaceutics, vol. 239, pp. 197-205, 2002.

[15] S. Jiang, J. Lv, M. Ding, Y. Li, H. Wang, and S. Jiang, "Release behavior of tetracycline hydrochloride loaded chitosan/poly(lactic acid) antimicrobial nanofibrous membranes", Materials Science and Engineering: $C$, vol. 59, pp. 86-91, 2016.

[16] K. A. Rieger and J. D. Schiffman, "Electrospinning an essential oil: Cinnamaldehyde enhances the antimicrobial efficacy of chito- san/poly(ethylene oxide) nanofibers", Carbohydrate Polymers, vol. 113, pp. 561-568, 2014.

[17] J. Song, S. J. A. Remmers, J. Shao, E. Kolwijck, X. F. Walboomers, J. A. Jansen, S. C. G. Leeuwenburgh, and F. Yang, "Antibacterial effects of electrospun chitosan/poly(ethylene oxide) nanofibrous membranes loaded with chlorhexidine and silver", Nanomedicine: Nanotechnology, Biology and Medicine, vol. 12, pp. 13571364, 2016.

[18] M. S. Kim, S. J. Park, B. K. Gu, and C.-H. Kim, "Polycaprolactone-Chitin Nanofibrous Mats as Potential Scaffolds for Tissue Engineering", Journal of Nanomaterials, vol. 2012, p. 9, 2012.

[19] "Dielectric Constant of Common solvents.xls [online]", Disponible en: http://depts.washington.edu/eooptic/linkfiles/ dielectric_chart[1].pdf.

[20] R. Jayakumar, H. Tamura, S. V. Nair, and T. Furuike, "Perspectives of Chitin and Chitosan Nanofibrous Scaffolds in Tissue Engineering", Tissue Engineering, 2010.

[21] K. Ohkawa, D. Cha, H. Kim, A. Nishida, and H. Yamamoto, "Electrospinning of Chitosan", Macromolecular Rapid Communications, vol. 25, pp. 1600-1605, 2004.

[22] C. F. Berghoff, "Desarrollo y caracterización de matrices compuestas Quitosano/Polímero sintético para regeneración de tejido óseo", Tesis doctoral. Facultad de Ciencias Exactas. Departamento de Ciencias Biológicas. Universidad Nacional de la Plata, p. 229, 2011.

[23] Z. H. L. K. Sun, "Preparations, properties and applications of chitosan based nanofibers fabricated by electrospinning", eXPRESS Polymer Letters, vol. 5, pp. 342?361, 2011.

[24] P. S. a. P. Supaphol, "Stability Improvement of Electrospun Chitosan Nanofibrous Membranes in Neutral or Weak Basic Aqueous Solutions", Biomacromolecules. American Chemical Society, vol. 7, pp. 2710-2714, August 20, 2006.

[25] M. V. Debandi, N. J. Francois, and M. E. Daraio, "Evaluación de distintas membranas para liberación in vitro de principios activos anticelulíticos", Avances en ciencias e ingeniería, vol. 2, pp. 97-105, 2011. 
[26] P. L. Ritger and N. A. Peppas, "A simple equation for description of solute release I. Fickian and non-fickian release from non-swellable devices in the form of slabs, spheres, cylinders or discs", Journal of Controlled Release, vol. 5, pp. 23-36, 1987.

[27] M. T. V. Iborra, "Desarrollo Galénico de preparados obtenidos por interacción del Ácido 5-amino salicílico con Halloysita", Tesis doctoral. Facultad de Farmacia. Departamento de Farmacia y Tecnología Farmacéutica. Universidad de Granada, pp. 1-307, 2008.

[28] Z. Li and C. Wang, "Effects of Working Parameters on Electrospinning", in OneDimensional nanostructures: Electrospinning Technique and Unique Nanofibers, o. p. m. e. a. http://electrospintech.com/beads.html\#. VyaaMkweSkp, Ed., ed Berlin, Heidelberg: Springer Berlin Heidelberg, pp. 15-28, 2013

[29] F. A. B. y. G. A. A. P. C. Caracciolo, "Matrices Poliuretánicas nanofibrosas obtenidas por el proceso de electrospinning”, $2 \check{r}$ Encuentro de Jóvenes Investigadores en Ciencia y Tecnología de Materiales. Posadas. Misiones. Asociación Argentina de Materiales. Divisió Polímeros. INTEMA. Univerisad de Mar de Plata, Pcia de Buenos Aires, 2008.

[30] T. Elzein, M. Nasser-Eddine, C. Delaite, S. Bistac, and P. Dumas, "FTIR study of polycaprolactone chain organization at interfaces", Journal of Colloid and Interface Science, vol. 273, pp. 381-387, 2004.

[31] S.-H. Chen, C.-H. Chen, Y. T. Fong, and J.-P. Chen, "Prevention of peritendinous adhesions with electrospun chitosan-grafted polycaprolactone nanofibrous membranes", Acta Biomaterialia, vol. 10, pp. 4971-4982, 2014.

[32] E. Á. A. H. Hernández Cocoletzi, O. Flores Agustin, E.L. Viveros Nava, E. Ramos Cassellis, "Obtención y caracterización de quitosano a partir de exoesqueletos de camarón”, Sociedad Mexicana de Ciencia y Tecnología de Superficies y Materiales, vol. 22, pp. 57-60, 2009.

[33] W.-T. Su, P.-S. Wu, and T.-Y. Huang, "Osteogenic differentiation of stem cells from human exfoliated deciduous teeth on poly $(\varepsilon$ caprolactone) nanofibers containing strontium phosphate", Materials Science and Engineering: $C$, vol. 46, pp. 427-434, 2015.

[34] G. V. Joshi, H. A. Patel, B. D. Kevadiya, and H. C. Bajaj, "Montmorillonite intercalated with vitamin B1 as drug carrier", Applied Clay Science, vol. 45, pp. 248-253, 2009.

[35] C.-S. Wu, "A comparison of the structure, thermal properties, and biodegradability of polycaprolactone/chitosan and acrylic acid grafted polycaprolactone/chitosan", Polymer, vol. 46, pp. 147-155, 2005.

[36] S. H. Murphy, G. A. Leeke, and M. J. Jenkins, "A Comparison of the use of FTIR spectroscopy with DSC in the characterisation of melting and crystallisation in polycaprolactone", $J$ Therm Anal Calorim, vol. 107, pp. 669-674, 2012.

[37] D. M. García Cruz, D. F. Coutinho, J. F. Mano, J. L. Gómez Ribelles, and M. Salmerón Sánchez, "Physical interactions in macroporous scaffolds based on poly $(\varepsilon$ caprolactone)/chitosan semi-interpenetrating polymer networks", Polymer, vol. 50, pp. 20582064, 2009.

[38] V. Balsamo, L. M. Gouveia, L. Herrera, E. Laredo, and B. Méndez, "Miscibilidad en Mezclas de Poli(Estireno-co-Anhídrido Maleico) y Poli( $\varepsilon$-Caprolactona) (SMA/PCL)", Revista Latinoamericana de Metalurgia y Materiales, vol. 24, pp. 17-30, 2004.

[39] F. S. Kittur, K. V. Harish Prashanth, K. Udaya Sankar, and R. N. Tharanathan, "Characterization of chitin, chitosan and their carboxymethyl derivatives by differential scanning calorimetry", Carbohydrate Polymers, vol. 49, pp. 185-193, 2002.

[40] E. V. R. Almeida, E. Frollini, A. Castellan, and V. Coma, "Chitosan, sisal cellulose, and biocomposite chitosan/sisal cellulose films prepared from thiourea/ $\mathrm{NaOH}$ aqueous solution", Carbohydrate Polymers, vol. 80, pp. 655-664, 2010.

[41] C. Albacete, A. Chiralta, and C. GonzálezMartíneza, "Efecto de la humedad y del glicerol en las transiciones de fase de biopolímeros: proteína de guisante y quitosano", Departamento de Tecnología de Alimentos, Instituto Universitario de Ingeniería de Alimentos para el Desarrollo, Universidad Politécnica de Va- 
lencia, Camino de Vera s/n, Valencia, España, pp. 1-20.

[42] J. H. Mina Hernández, S. Anderson Otero, C. A. Bolaños Arbelaez, and E. F. Toro Perea, "Preparación y caracterización físico-química y térmica de mezclas binarias de resina mopa-mopa (elaegia pastoensis mora) y policaprolactona (PCL)", Revista Latinoamericana de Metalurgia y Materiales, vol. 32, pp. 176-184, 2012.

[43] L. B. Rodríguez, M. S. Ballestero, J. V. Baudrit, M. C. Elizondo, and S. M. Carballo, "Estudio cinético de la degradación térmica de quitina y quitosano de camarón de la especie ?heterocarpus vicarius? empleando la técnica termogravimétrica en modo dinámico", Revista Iberoamericana de Polímeros, vol. 11, pp. 558-573, 2010.

[44] E. P. S. Tan, S. Y. Ng, and C. T. Lim, "Tensile testing of a single ultrafine polymeric fiber", Biomaterials, vol. 26, pp. 1453-1456, 2005.

[45] S. Y. Chew, T. C. Hufnagel, C. T. Lim, and K. W. Leong, "Mechanical properties of single electrospun drug-encapsulated nanofibres", Nanotechnology, vol. 17, pp. 3880-3891, 2006.

[46] R. C. Hibbeter, "Mecánica de materiales", 7a ed., Person Educación, p. 876, 2006.
[47] E. Y. Gómez-Pachón, F. M. Sánchez-Arévalo, F. J. Sabina, A. Maciel-Cerda, R. M. Campos, N. Batina, I. Morales-Reyes, and R. VeraGraziano, "Characterisation and modelling of the elastic properties of poly(lactic acid) nanofibre scaffolds", Journal of Materials Science, vol. 48, pp. 8308-8319, 2013.

[48] A. Cooper, R. Oldinski, H. Ma, J. D. Bryers, and M. Zhang, "Chitosan-based nanofibrous membranes for antibacterial filter applications", Carbohydrate Polymers, vol. 92, pp. 254-259, 2013.

[49] E. Muñoz Prieto, Bernabé Rivas, Julio Sánchez, "Natural Polymer Grafted with Synthetic Monomer by Microwave for Water Treatment - A Review", Ciencia en Desarrollo, vol. 4, no.1, pp. 219-240, 2012.

[50] J. C. S. Pech, "Obtención de un membrana tubular de ácido Poli (láctico-co-glicólico) y Policaprolactona, mediante la técnica de electrohilado para la ingeniería en tejidos de la uretra", Tesis de Maestría, vol. Centro de Investigación Científica de Yucatán, A.C. Posgrado en Materiales Poliméricos. Mérida, Yucatán, 2014. 